\title{
Annotated ESTs from various tissues of the brown planthopper Nilaparvata lugens: A genomic resource for studying agricultural pests
}

\author{
Hiroaki Noda*1, Sawako Kawai ${ }^{1}$, Yoko Koizumi1 ${ }^{1}$, Kageaki Matsui ${ }^{1,3}$, \\ Qiang Zhang1, Shigetoyo Furukawa², Michihiko Shimomura ${ }^{2}$ and
} Kazuei Mita ${ }^{1}$

\begin{abstract}
Address: ${ }^{1}$ National Institute of Agrobiological Sciences, Owashi, Tsukuba, Ibaraki 305-8634, Japan, ${ }^{2}$ Mitsubishi Space Software Co. Ltd, Takezono, Tsukuba, Ibaraki 305-0032, Japan and ${ }^{3}$ Magnabeat Inc., Goi-kaigan, Ichihara, Chiba 209-8551, Japan

Email: Hiroaki Noda* - hnada@affrc.go.jp; Sawako Kawai - kawako@affrc.go.jp; Yoko Koizumi - ykoizumi@affrc.go.jp;

Kageaki Matsui - jingming.wang@chisso.co.jp; Qiang Zhang - rosess@affrc.go.jp; Shigetoyo Furukawa - furukawa@mi.mss.co.jp; Michihiko Shimomura - shimomur@mi.mss.co.jp; Kazuei Mita - kmita@affrc.go.jp

* Corresponding author
\end{abstract}

\section{Published: 3 March 2008}

BMC Genomics 2008, 9:117 doi:10.1186/1471-2164-9-117
Received: II September 2007

Accepted: 3 March 2008

This article is available from: http://www.biomedcentral.com/I47I-2164/9/II7

(C) 2008 Noda et al; licensee BioMed Central Ltd.

This is an Open Access article distributed under the terms of the Creative Commons Attribution License (http://creativecommons.org/licenses/by/2.0), which permits unrestricted use, distribution, and reproduction in any medium, provided the original work is properly cited.

\begin{abstract}
Background: The brown planthopper (BPH), Nilaparvata lugens (Hemiptera, Delphacidae), is a serious insect pests of rice plants. Major means of BPH control are application of agricultural chemicals and cultivation of BPH resistant rice varieties. Nevertheless, BPH strains that are resistant to agricultural chemicals have developed, and BPH strains have appeared that are virulent against the resistant rice varieties. Expressed sequence tag (EST) analysis and related applications are useful to elucidate the mechanisms of resistance and virulence and to reveal physiological aspects of this non-model insect, with its poorly understood genetic background.

Results: More than 37,000 high-quality ESTs, excluding sequences of mitochondrial genome, microbial genomes, and rDNA, have been produced from 18 libraries of various BPH tissues and stages. About 10,200 clusters have been made from whole EST sequences, with average EST size of $627 \mathrm{bp}$. Among the top ten most abundantly expressed genes, three are unique and show no homology in BLAST searches. The actin gene was highly expressed in BPH, especially in the thorax. Tissue-specifically expressed genes were extracted based on the expression frequency among the libraries. An EST database is available at our web site.

Conclusion: The EST library will provide useful information for transcriptional analyses, proteomic analyses, and gene functional analyses of BPH. Moreover, specific genes for hemimetabolous insects will be identified. The microarray fabricated based on the EST information will be useful for finding genes related to agricultural and biological problems related to this pest.
\end{abstract}

\section{Background}

The brown planthopper (BPH, Nilaparvata lugens) attacks rice plant and sucks fluid from the vascular bundle. Heavy infestation in the field causes hopper burn: complete death of the rice plants. In addition to sucking damage, $\mathrm{BPH}$ is a vector for the rice ragged stunt virus (RRSV) and rice grassy 
stunt virus (RGSV) [1]. Attack of this pest has caused intermittent serious famines in the East Asia since ancient times; it became conspicuous in the Southeast Asia after the so-called Green Revolution of the 1960s. Actually, $\mathrm{BPH}$ shows two wing forms, long (macropterous) and short (brachypterous) ones, in its adult stage. Macropterous adults fly long distances and invade rice-growing area. Most females of the subsequent generation of the immigrants are brachypterous - adapted for reproduction - and produce numerous offspring in rice fields. The wing dimorphism is induced by environmental stimuli during nymphal stages. These biological properties of $\mathrm{BPH}$ are closely related to BPH distribution, BPH reproduction, and rice plant damage.

Control methods of BPH primarily include the application of insecticides; various chemicals, organo-phosphorous, carbamate, pyrethroid, and neonicotinoid insecticides have been used in the field. However, insecticide application poses two problems: appearance of insecticide-resistant planthoppers $[2-4]$; and stimulation of planthopper propagation by insecticide treatment, known as resurgence [5,6]. Planthopper-resistant varieties of rice, which are widely cultivated in Asian countries, are also used as means of controlling BPH. However, cultivation of the planthopper-resistant varieties has engendered new virulent strains of BPH that can attack the resistant varieties [7]. Elucidation of rice plants' genes that increase resistance against planthoppers and $\mathrm{BPH}$ virulence mechanisms against the resistant rice plants have become important tasks. The former subject, that of resistance genes of rice plants, is studied extensively based on positional cloning, so-called map-based cloning procedures [8-10]. The latter problem, appearance of virulent strains of planthopper, awaits precise studies based on recent molecular approaches.

Rice planthoppers have been studied from ecological and physiological viewpoints but they have remained poorly investigated in genetic terms. A valid method for introducing molecular studies into insects without a genetic background is construction of an EST database. Information of genes working in various tissues at various growth stages is extremely useful for molecular functional study in biology. The ESTs of many insects have been accumulated; those of target insects have expanded to include agricultural pests, such as the migratory locust [11], aphids [1214], whitefly [15], and armyworm [16]. Generation of ESTs in these agricultural pests is a first step to development of genomic resources for helping to solve agricultural problems.

The order Hemiptera, which includes Nilaparvata lugens, comprises two suborders: Heteroptera and Homoptera. Genome studies of Heteroptera are poor and a small-scale
EST study have been reported [17], although large scale ESTs have been generated from homopteran insects, the pea aphid Acyrthosiphon pisum [14], the whitefly Bemisia tabaci [15], the green peach aphid Myzus persicae [18], the cotton aphid Aphis gossypii (>8,300 ESTs), and the glassywinged sharpshooter Homalodisca coagulata $(>20,000$ ESTs). In addition, EST studies have been reported for the cereal aphid Rhopalosiphum padi [13] and the brown citrus aphid Toxoptera citricida [12]. A whole genome sequencing project is undertaken in a model insect A. pisum.

The present study was designed to acquire elusive EST data from different tissues and to provide data for discovery and identification of genes involved in fundamental biological phenomena and agricultural problems related to $\mathrm{BPH}$. We also intend to undertake microarray-based studies in this planthopper species. We have collected about 37,000 high-quality EST data and more than 10,000 clustered unigenes from various tissues of this important pest. The datasets are available at DNA databases under the following accession numbers: [DDBJ/EMBL/GenBank: DB820956-DB858077] and at the website for BPH cDNA [19].

\section{Results and Discussion Quality control of cDNA libraries}

We produced 18 libraries (Table 1) from 15 different tissues or stages of the brown planthopper (BPH) to obtain various transcripts and to extract tissue-specifically expressed genes or planthopper-specific genes from the libraries. Two vectors, lambda-ZAP II and pGEM, were used for construction of the cDNA libraries. The former phage libraries were used in the early stages of study; later we constructed pGEM libraries using SMART technology. Single-path sequencing of the CDNA, which provided the sequence from the 5 ' region of mRNA, was done in each library. In all, more than 50,000 clones were processed, and 42,901 high-quality sequences of more than $299 \mathrm{bp}$ long were selected. Vector sequences franking with the EST sequences were trimmed manually. Sequence contamination of lambda-ZAP II vector or lambda phage ( 87 clones) and the host organism Escherichia coli (130 clones) were deleted from the libraries based on in-house BLAST searches. The sequences of three major commensalistic viruses in the planthopper, NLRV [20,21], NLCXV [22], and Hi-PV [22,23], of which numbers in the ESTs were 0,2 , and 574 clones, respectively, were discarded. The Hi-PV sequences were mainly found from libraries of the female (MA) and male (MB) midgut, which is a major infection and propagation site of Hi-PV [24]. Mitochondrial sequences, which formed about $11 \%$ of the selected sequences $(4,653 / 42,108)$, were subsequently eliminated. Ribosomal RNA (214 clones) and retrotransposon R2 (90 clones) sequences were also eliminated from the remaining ESTs. The resultant 37,144 sequences were further 
Table I: List of the EST database of Nilaparvata lugens

\begin{tabular}{|c|c|c|c|c|c|c|}
\hline Library & Tissue/sex/stage & Vector used & No. of clones & Average length (bp) & $\% " N "$ & No. of clusters \\
\hline AA & Abdomen, female, $0-I$ day & ZAP & 609 & 589.7 & 0.014 & 435 \\
\hline$A B$ & Abdomen, female, $0-I$ day & ZAP & 1027 & 601.9 & 0.011 & 667 \\
\hline$A C$ & Abdomen, male, $0-I$ day & ZAP & 588 & 599.7 & 0.022 & 493 \\
\hline$A D$ & Abdomen, male, $0-I$ day & ZAP & 967 & 594.9 & 0.102 & 726 \\
\hline EA & Egg, $0-1.5$ day & pGEM & 3726 & 652.0 & 0.051 & 2371 \\
\hline EB & Egg, 3-5 day & PGEM & 2055 & 576.3 & 0.076 & 941 \\
\hline $\mathrm{HA}$ & Head, female, $0-I$ day & ZAP & 777 & 520.6 & 0.018 & 111 \\
\hline HT & Head-thorax, male, $0-I$ day & ZAP & 2555 & 673.9 & 0.070 & 1132 \\
\hline MA & Midgut, female, $0-5$ day & PGEM & 3594 & 637.5 & 0.051 & 1252 \\
\hline$M B$ & Midgut, male, $0-5$ day & PGEM & 2095 & 606.4 & 0.117 & 847 \\
\hline NA & Whole nymph, Ist instar & PGEM & 3269 & 633.8 & 0.096 & 1714 \\
\hline NB & Whole nymph, 4th instar & ZAP & 3710 & 624.7 & 0.058 & 1749 \\
\hline OA & Ovary, 0-I day & ZAP & 967 & 511.5 & 0.119 & 689 \\
\hline OB & Ovary, 4-5 day & ZAP & 822 & 601.9 & 0.028 & 329 \\
\hline OC & Ovary, 4-5 day & ZAP & 2225 & 604.4 & 0.079 & 989 \\
\hline SG & Salivary glands, female, $0-5$ day & pGEM & 2383 & 640.8 & 0.083 & 723 \\
\hline TA & Testis, $0-1$ day & ZAP & 1525 & 575.9 & 0.045 & 895 \\
\hline $\mathrm{TH}$ & Thorax, 0-I day & ZAP & 4228 & 693.1 & 0.029 & 1657 \\
\hline Total & & & 37122 & 626.7 & 0.065 & $1026 \mid$ \\
\hline
\end{tabular}

ZAP, lambda ZAP II (pBluescript) phage vector; pGEM, pGEM-t plasmid vector; \%"N", percentage of ambiguous nucleotides. Ovary and testis includes the accessory glands of the reproductive organs. Clustering was performed using CLOBB [25]. ESTs are deposited in the DNA databases under accession numbers DB20956-DB858077 (37,122 entries).

checked for short vector sequences using NCBI VecScreen. Chimeric sequences, which include two or more different mRNA sequences in an EST sequence, were then surveyed. ESTs were clustered based on the result of BLASTN (95\% identity, $80 \%$ cover ratio); positional distributions of ESTs in each group were shown on a computer screen using the graphical overview of NCBI BLAST. The chimeric sequences were checked manually to determine whether two contigs were included in an assembled group or not. The chimeric sequences were usually found as those connecting two EST contigs or those having sequence extension to other members. Some, but not all, chimeric sequences appear to have been deleted. Finally, 37,122 cleaned sequences were deposited in the BPH database. Some ESTs, however, might retain several extra nucleotides at the $5^{\prime}$ end. The average length of all ESTs was $626.7 \mathrm{bp}$; the range of most abundant sizes of sequences was 651-700 bp (Fig. 1). Ambiguous nucleotides, which are shown in "N", were $0.065 \%$ on average ( 0.4 bp per each EST) among all EST sequences (Table 1).

\section{EST clustering}

All cleaned EST sequences were subjected to clustering using two clustering protocols, Cluster on the basis of BLAST similarity (CLOBB) [25] and Method of Combined BLAST and PhredPhrap (CBP) [26]. Mainly, CLOBB was used but the results of clustering generally differ among protocols. For that reason, two clustering methods were compared. First, CLOBB analyses were performed using parameters of $95 \%$ identity and 50 bp coverage (Table 1 ), resulting in 10,261 clusters $(6,196$ singletons and 4,065 contigs) (Fig. 2). Sequence assembly of the members of each contig, however, sometimes showed sequence variation (data not shown). This seems to be attributable to the following reasons: planthopper specimens collected from the stock culture possess heterogeneity in genome sequences among individuals. In addition, more than one similar gene was encoded on the genome. The second protocol, CBP, created 12,303 clusters $(8,053$ singletons and 4,250 contigs) using the parameters in additive manner,

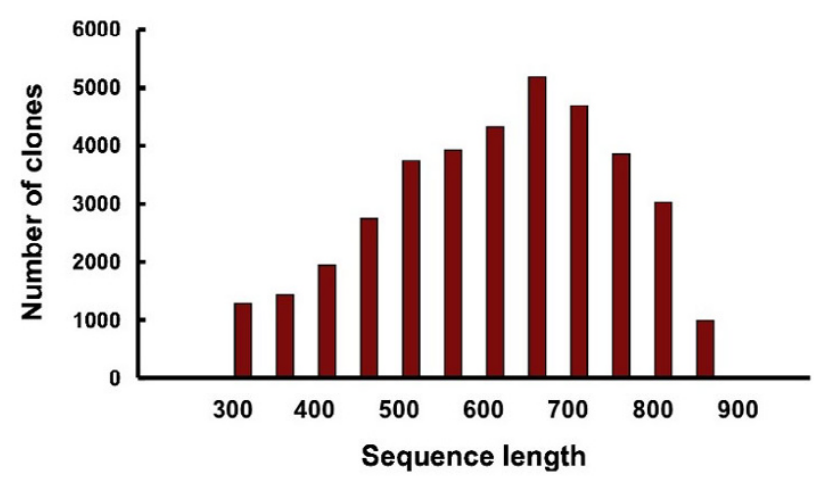

Figure I

EST size distribution. ESTs of more than 299 bp were grouped by each 50 bp. 


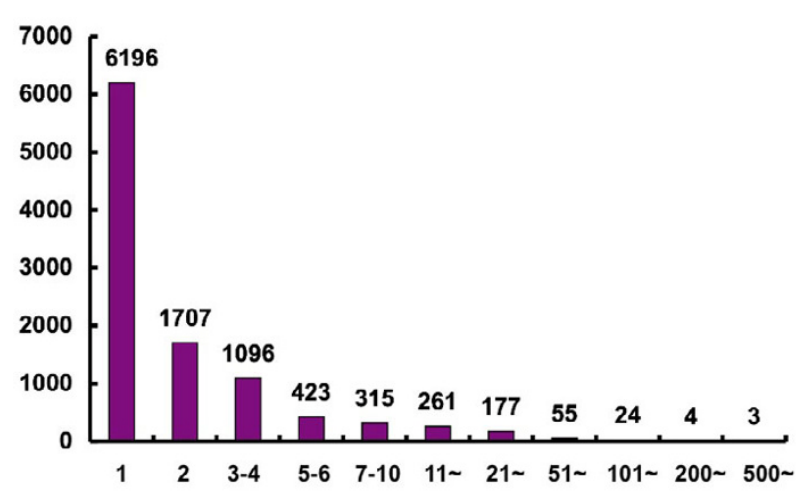

Figure 2

Relation between the number of clusters (vertical) and cluster size (horizontal). Clusters were calculated using the CLOBB clustering algorithm [25]. The number of clusters (unigenes) was 10,26I, with 6,196 singletons.

$>97 \%$ identity and $>90$ bp coverage [26]. Actually, CBP tended to separate the members of each contig, whereas CLOBB sometimes included much sequence variation in each contig. A BPH database [19] was constructed based on CBP clustering results.

\section{Comparison of two cloning systems for EST analyses}

In the EST project for small insects, the whole body is often used as the starting material because it is difficult to obtain a sufficient amount of total RNA or mRNA otherwise. In fact, female adult BPHs are about 4-mm long; the RNA amount from the dissected small tissue is therefore insufficient for a phage library. We used two cloning systems: lambda ZAP II phage (phage library) and pGEM plasmid (plasmid library). In general, the phage libraries are better than the plasmid libraries because the former can clone a larger insert DNA and create a larger number of clones than the latter. However, cloning into the pGEM plasmid is easier than that into ZAP II phage; moreover, it can be performed using a smaller amount of mRNA sample. Here, we compared the quality of the plasmid libraries with the phage libraries in two respects: the rate of vector contamination and the unigene ratio in each library.

First, contamination of cloning vectors in the EST sequences was compared in 42,901 ESTs $(23,684$ ESTs in phage libraries and 19,217 in plasmid libraries) using inhouse BLAST, as described above. In the phage libraries, 87 lambda phage sequences were found, although no pGEM vector sequences were detected in the plasmid libraries. Host bacterial genome contamination was found in 129 clones in the phage libraries and one in the plasmid libraries. The plasmid library is excellent from the viewpoint of contamination of vector sequences and host bacterial genome sequences.

Second, unigene ratios were calculated against the number of ESTs in each library. In the plasmid libraries, cDNA was prepared using SMART technology (Clontech Laboratories, Inc. USA), which uses PCR amplification. Therefore, the possibility is considered that biased amplification reduces the variety of cDNA. This might consequently decrease the ratio of unigenes in ESTs. Figure 3 shows the relation between the unigene ratio and the number of analyzed ESTs. The vertical axis shows the ratio (number of unigenes/number of ESTs), and the horizontal axis shows the number of ESTs analyzed. The number of unigenes corresponding to the number of clusters was calculated using CLOBB (Table 1). No marked low unigene ratio in the plasmid library was observed; rather, the ratio was varied among libraries (Fig. 3). One phage library (HA, female head) showed an extremely low unigene ratio (0.143), which was excluded for calculation of regression curve in Fig. 3. No remarkable disadvantage was observed in the plasmid libraries in terms of the unigene ratio. However, consideration of biased amplification and of polymerase amplification error is required for EST sequences of the plasmid libraries. A low amplifica-

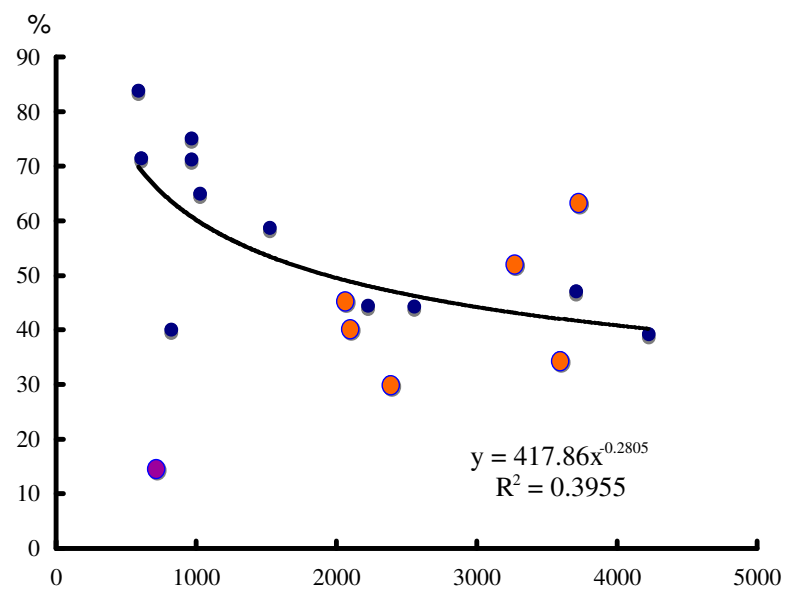

Figure 3

Comparison of two different vector libraries in the ratio of unigenes. The unigene rate against the number of ESTs analyzed was plotted for 18 different tissue libraries. Vertical axis, percentage (number of unigenes/the number of ESTs analyzed); horizontal axis, the number of ESTs analyzed in each library. Blue, the libraries of lambda-ZAP II; orange, the libraries of $P G E M$. The CLOBB algorithm was used for unigene calculation. The HA (female head) library, shown in violet, was excluded from calculation of the regression curve because this library showed an extremely low unigene rate against the number of ESTs $($ I I I/777 $=0.143)$. 
tion cycle number is preferable for construction of plasmid libraries.

\section{Abundantly expressed genes}

Most abundantly expressed genes were extracted from the 37,122 ESTs based on the CLOBB clustering results. The contigs that included the top ten members are presented in Table 2. Contigs containing many ESTs were simply selected from the top, although the numbers of ESTs differ among libraries, which appears to affect the ranking of highly expressed genes.

The actin gene was the most abundantly expressed in this species: CLOBB clustering formed a single group of actin gene as the biggest contig. Sequence alignment of the EST members showed that the actin gene of BPH had a coding capacity of 376 amino acid residues with a few single nucleotide polymorphisms among EST members. The actin gene is highly expressed in the thorax (TH and HT). This result is in accordance with the planthopper internal structure: the thorax is rich in muscle. The ESTs of the myosin gene, the eighth highly expressed gene, is also found mainly in TH and HT libraries.

A second abundantly expressed gene (MB3851 representative), which was mainly found in midgut libraries, showed no homology in the BLAST searches. This contig showed a coding capacity of a protein of 180 residues (Fig. 4). InterProScan [27] indicated that the first 18 amino acids corresponded to a signal peptide. More than $96 \%$ of ESTs belong to the male and female midgut libraries (MA and $M B$ ). Another five libraries, egg (EA and EB), 1st instar nymph (NA), salivary gland (SG), and testis (TA) libraries respectively contained this gene sequence in small numbers: six, four, one, five, and five. Subsequently, RT-PCR was performed to examine the expression stages of this gene in BPH. In all, 10 individuals of each stage (third instar nymph - 3-day-old adult) were tested. Gene expres- sion, however, showed no uniformity among individuals and through the stages. Some individuals showed the PCR product and some did not (Fig. 5). Quantitative RT-PCR showed a parallel level of expression with standard ribosomal protein L4 in the ovary, midgut and testis (data not shown). Therefore, the RNA level of this gene seems to be high in $\mathrm{BPH}$. The gene expression pattern was unusual. For that reason, genomic PCR was performed to examine whether this gene is coded in the BPH genome. However, we failed to obtain a PCR product from the genomic DNA using various combinations of 11 primers throughout the gene sequence and various amplification conditions. Genome-coded genes, such as the elongation factor 2 gene and ribosomal protein L4 gene, which are one-copy genes in Drosophila melanogaster, were amplified in similar conditions. This result suggests that the MB3851 gene is not in the BPH genome but rather came from an exogenous source. In fact, BPHs possess intracellular yeastlike symbiotes (YLS) in the fat body [28], but this gene was not found in the genome of YLS by a PCR-based survey. Moreover, the expression of this gene was observed in the tissues where YLS are not distributed. Bacteria in the gut do not also appear to be the source of this highly expressed gene because expression was not restricted to the gut. Moreover, genomic PCR from the intestine sample did not give a PCR product. A possible explanation is that this transcript or RNA derived from an exogenous source of $\mathrm{BPH}$ such as a virus or infectious RNA. Three virus species are known in BPH $[20,22,23]$; a different virus might be the source of this gene. Transmitted dsRNA replicons are often found in plants and fungi $[29,30]$ and have been reported in insects [31].

Thirdly, an uncustomary gene, which was highly recovered from the salivary gland library (SG), was ranked. The gene product was rich in serine and alanine; some repeated amino acid sequences were found, suggesting that this gene product is a structural protein in BPH. This

Table 2: Top ten genes frequently appearing in the planthopper whole EST library

\begin{tabular}{|c|c|c|c|c|}
\hline No. & Representative & No. of members & BLASTN & BLASTX \\
\hline I & AA0004 & 727 & actin & actin \\
\hline 2 & EA0I06 & 577 & n.h. & n.h. \\
\hline 3 & HA0070 & 542 & mucin-like protein & mucin-like protein \\
\hline 4 & AA0350 & 282 & trypsin-like protease & trypsin-like protease \\
\hline 5 & AAOII6 & 254 & ribosomal protein S2 & ribosomal protein $\mathrm{S} 2$ \\
\hline 6 & AA00I3 & 238 & vitellogenin & vitellogenin \\
\hline 7 & AA0383 & 228 & n.h. & low homology \\
\hline 8 & AA0260 & 186 & myosin light chain & myosin light chain \\
\hline 9 & AA0046 & 171 & enolase & enolase \\
\hline 9 & AB058I & 171 & n.h. & n.h. \\
\hline
\end{tabular}

The number of members was calculated using the CLOBB clustering algorithm. Genes are shown by the EST number that is representative of the cluster members. AA0383 is the same cluster member of OC2756, which is highly expressed in the ovary, as shown in Table 4. "n.h." denotes no homology in BLAST searches (see Gene annotation in Methods). 
$\begin{array}{llrrr}10 & 20 & 30 & 40 & 50\end{array}$

AАAАTATAAAAACTTGTTTTAAAACCTTTTAAACCAGATAGTTTGGCATCATAACATATC

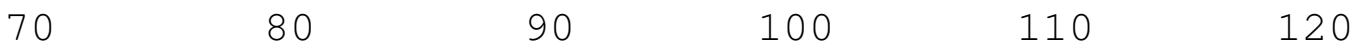
TACATCTTTCGTATGTGGATTCAAATTTTTGTCCAGGCGTGTTGGTGTTGCTTCATGGCT

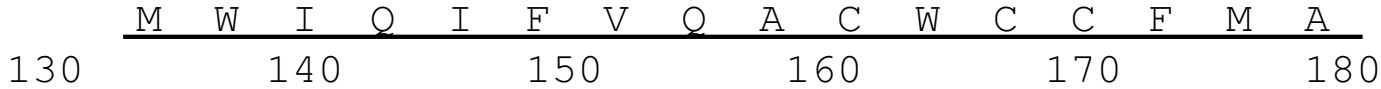

TACGCGGCAAATAGATTCGGAAAACGCGAGGACGATTATGAAGGTGACGAGGGAGAGAAA

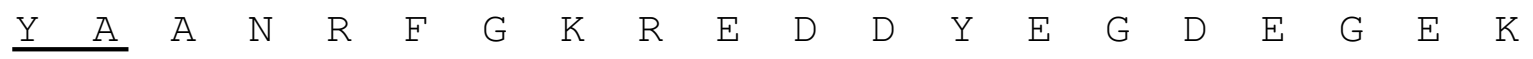

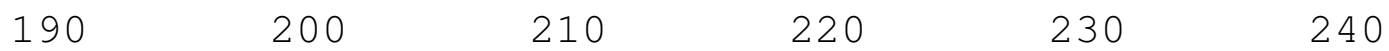

GGGGATGAAGACTTCCCGGCCCATGCAGCCGTAGCTCAAGCTGTTAGGGATTTTGCCCGG

$\begin{array}{lllllllllllllllllllllllll}G & D & E & D & F & P & A & H & A & A & V & A & Q & A & V & R & D & F & A & R\end{array}$

$\begin{array}{lllll}250 & 260 & 270 & 280 & 290\end{array}$

CAAAGGAAAACTCGCGAAGGATATATGGCTGAATGCAAAAGCCAGTACGAAGCCCCAGGA $\begin{array}{llllllllllllllllllll}Q & R & K & T & R & E & G & Y & M & A & E & C & K & S & Q & Y & E & A & P & G\end{array}$

$\begin{array}{lllll}310 & 320 & 330 & 340 & 350\end{array}$

TGGCTTACTCAGGCATCTACATCATCAAAGCCTCCTCCTGCTGTCAGACCCGATTTAGCC $\begin{array}{llllllllllllllllllllllllll}W & \mathrm{~L} & \mathrm{~T} & \mathrm{Q} & \mathrm{A} & \mathrm{S} & \mathrm{T} & \mathrm{S} & \mathrm{S} & \mathrm{K} & \mathrm{P} & \mathrm{P} & \mathrm{P} & \mathrm{A} & \mathrm{V} & \mathrm{R} & \mathrm{P} & \mathrm{D} & \mathrm{L} & \mathrm{A}\end{array}$

$\begin{array}{llllr}370 & 380 & 390 & 400 & 410\end{array}$

CAATTAGGTCCTTCCATCCCGTCAGGGAAAACAAGGGAAGAGAGACTGGACAGAATAGAG $\begin{array}{lllllllllllllllllllllllllllll}Q & L & G & P & S & I & P & S & G & K & T & R & E & E & R & L & D & R & I & E\end{array}$ $\begin{array}{llllr}430 & 440 & 450 & 460 & 470\end{array}$

AAGCGTATCGAGCAAATGCAGCAGATCCTCCTCACGACTTCTCTTCGGGTGATAGCGATT $\begin{array}{llllllllllllllllllll}K & R & I & E & Q & M & Q & Q & I & L & L & T & T & S & L & R & V & I & A & I\end{array}$ $490 \quad 500 \quad 510 \quad 520 \quad 530 \quad 540$

GATGAGTGTGCTAAGAAAACACAGGGGATGCTGCAGGCGCTTATAGAGCAGCTGAAATAC $\begin{array}{llllllllllllllllllll}\mathrm{D} & \mathrm{E} & \mathrm{C} & \mathrm{A} & \mathrm{K} & \mathrm{K} & \mathrm{T} & \mathrm{Q} & \mathrm{G} & \mathrm{M} & \mathrm{L} & \mathrm{Q} & \mathrm{A} & \mathrm{L} & \mathrm{I} & \mathrm{E} & \mathrm{Q} & \mathrm{L} & \mathrm{K} & \mathrm{Y}\end{array}$ $\begin{array}{lllll}550 & 560 & 570 & 580 & 590\end{array}$ ACTAAGGCTCCTCCTCCTAGGCCCGTTGAgGTGGATAATCGACAACCTTTTGTCCCAGGA $\begin{array}{lllllllllllllllllllll}\mathrm{T} & \mathrm{K} & \mathrm{A} & \mathrm{P} & \mathrm{P} & \mathrm{P} & \mathrm{R} & \mathrm{P} & \mathrm{V} & \mathrm{E} & \mathrm{V} & \mathrm{D} & \mathrm{N} & \mathrm{R} & \mathrm{Q} & \mathrm{P} & \mathrm{F} & \mathrm{V} & \mathrm{P} & \mathrm{G}\end{array}$
610
620
630
640
650
660

TTTGCTAAGCGTTAGTTGTCTTAGTACCCCCTGGCAGTTCGGCTCTGAAGTGCAATCGGG $\mathrm{F} \quad \mathrm{A} \quad \mathrm{K} \quad \mathrm{R}$ *
670
680
690
700
710
720

GAAAGGAACATAAAGAAATGAAGTTTTAAAACGAGGCGGAAATAAGATTTTTAAAACAAG
730
740
750
760
770

TTCTCTTGCGCGCTTtgTGTtGCTAGTTTGATGTGTCTGTTTAAAAAAAAAAAAAAA

\section{Figure 4}

cDNA nucleotide sequence and putative deduced amino acid sequence of EST clone MB385I. The nucleotide sequence was determined based on the sequence alignment data of cluster members of MB385I. Stop codons are found at the upstream region of the putative first methionine. An InterProScan sequence search [27] showed a signal peptide in the first 18 amino acids (underlined). No homology was found in the DNA and protein databases. 
Nymphs
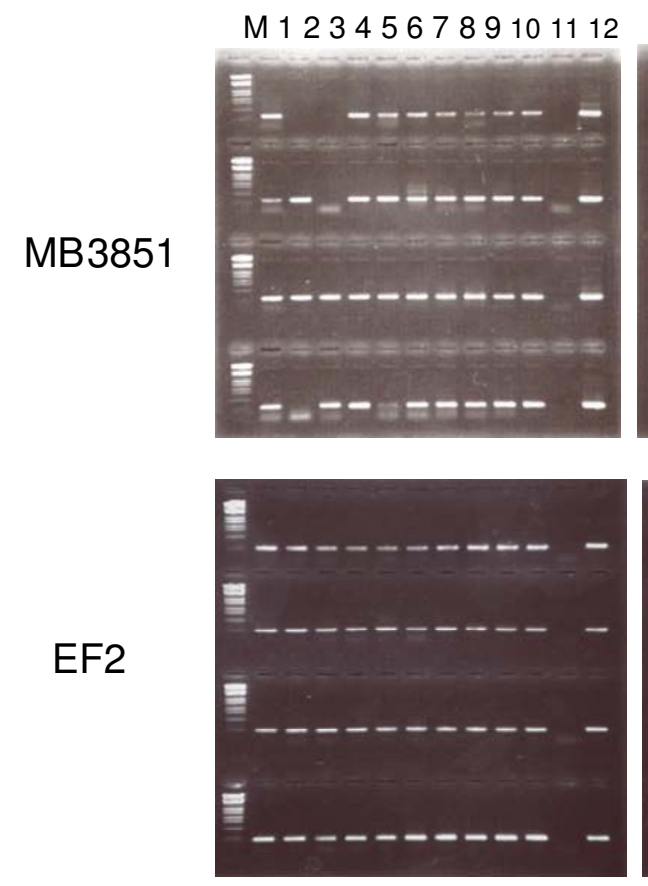

Adult females
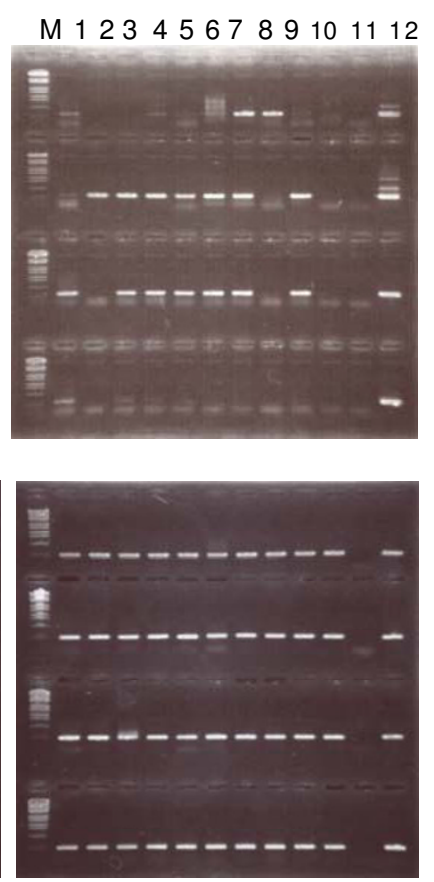

Adult males
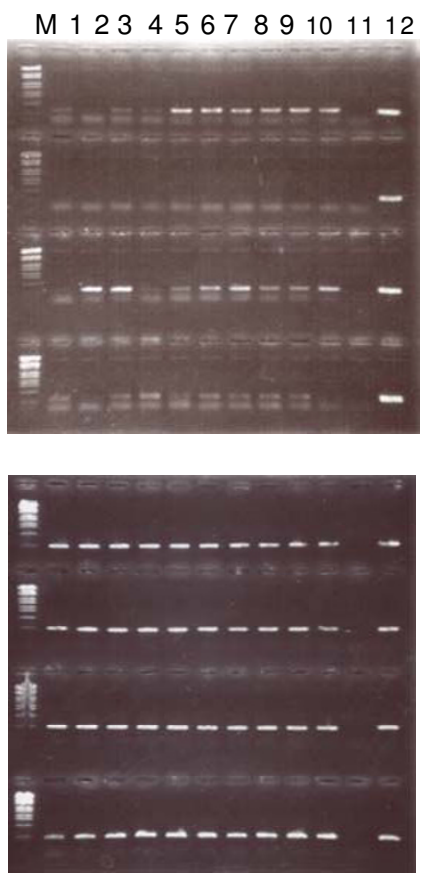

\section{Figure 5}

RT-PCR of EST clone MB385 I at various stages of BPH. PCR products amplified from I0 individual samples at each stage were electrophoresed on agarose gel. These samples were tested for positive amplification using a control PCR primer pair of elongation factor 2 gene (EF2) of BPH. Stage-dependent amplification was not clearly observed. Left panel: first row, 0-day-old third instar nymphs; second row, I-day-old fourth instar nymphs; third row 0-day-old fifth instar nymphs; fourth row, I-day-old fifth instar nymphs. Center panel: first row, 0-day-old female adults; second row, I-day old female adults; third row, 2-day-old female adults; fourth row, 3-day-old female adults. Right panel: first row, 0-day-old male adults; second row, I-day-old male adults; third row, 2-day-old male adults; fourth row, 3-day-old male adults. M, marker (lambda EcoTI4I digest); I-I0, individual samples; I I, negative control of no template; I2, positive control.

gene showed high homology to the gene expressed in the small brown planthopper, Laodelphax striatellus, which is annotated as mucin-like protein [accession number AAS88902]. Mucin is a heavily glycosylated protein forming a polymeric structure. It functions as mucosal barriers in some tissues. Planthoppers are vascular feeders and secrete coagulable saliva from the salivary glands for stylet feeding [32]. The protein of this gene product might be related to planthopper feeding. The predicted amino acid product, however, shows no homology with Drosophila mucin [AAF49596] [33].

Two enzyme genes, trypsin-like protease gene and enolase gene, were highly expressed in the planthopper. The protease was expressed in the midgut, showing expression in the libraries that contained the gut, $\mathrm{AA}, \mathrm{AB}, \mathrm{MA}, \mathrm{MB}, \mathrm{NA}$, $\mathrm{NB}$, and TH. About $97 \%$ of EST was recovered from the midgut libraries $\mathrm{MA}$ and $\mathrm{MB}$. The trypsin-like protease apparently works for food digestion. This gene corresponds to AJ316142 reported in $\mathrm{BPH}$ [34]. On the other hand, enolase expression was found from a wide range of libraries, including the libraries of the salivary glands, ovary, and testis. Enolase is an essential glycolytic enzyme that catalyzes the conversion of 2-phosphoglycerate. Other highly expressed enzyme genes in BPH were ATP synthase subunit C (top 14th), arginine kinase (top 16th), and carboxylesterase (top 18th). The former two genes work for energy production. The carboxylesterase is related to insecticide resistance by catalyzing the insecticidal compounds $[3,35]$.

Another notable gene was vitellogenin or vitellogenin-like protein gene. Results of CLOBB clustering showed that 238 ESTs belong to the vitellogenin gene cluster. The gene sequences of vitellogenin or vitellogenin-like proteins were not identical and were composed of several varied sequences. The fat body is the principal site of production of this yolk protein precursor in arthropods [36]. The expression of the vitellogenin gene, however, occurred throughout the female planthopper body; many ESTs (61 
clones) were found in the salivary gland library (SG). No EST of vitellogenin was found in the libraries of the egg, nymphal, and male libraries in BPH. However, similar genes were found in male libraries: further precise analysis is necessary. The whitefly, Bemisia tabaci, a homopteran insect like BPH, shows much expression of vitellogenin in adults [15].

Two genes of low or no homology were ranked at seventh and ninth (Table 2). The gene AA0383 was found in libraries of the female gonad $(\mathrm{OA}, \mathrm{OB}, \mathrm{OC})$ and the female abdomen $(\mathrm{AA}, \mathrm{AB})$, which contained the gonad. This result suggests that this gene is specifically expressed in the female gonad. This gene is the same as the female gonad-sepcifically expressed gene OC2756 described below. The cDNA size was short, about $500 \mathrm{bp}$, exhibiting the longest coding ability of 113 residues. The putative amino acid sequence was MSSKLFFVLATLALSALLSATESDAVYSNYALGSYGGYAYPS YAYPYYGYGYPYYSYGYPYYGYRYPYYSYGYPYYSYGYPYY SYGYPYYGYGGYGGYPYGGYGAYPGVGCVA， suggesting that this gene codes for a structural protein that is rich in tyrosine (39/113) and glycine (20/113). In-situ hybridization of this gene sequence showed specific expression in the lateral oviduct of the ovary as described later. Actually, BPH has swelled lateral oviducts, which become large and produce white material during maturation. This gene product seems to be a material that is secreted with oviposition.

The gene of no homology at ninth high expression in BPH (EST clone AB0581, 171 ESTs) was expressed in the midgut. In all, 167 ESTs were in the libraries of MA or MB, and each EST was found in $\mathrm{AB}, \mathrm{AC}, \mathrm{NA}$, and NB libraries, whose samples contain the midgut. The specific expression in the midgut was confirmed using RT-PCR; no RTPCR products were observed from the ovary and testis. This gene showed about $600 \mathrm{bp}$ of cDNA size and coding capacity of 101 residues. The members of the EST cluster were composed of two variant sequences, especially in the 3'UTR. The two groups showed two amino acid differences in putative amino acid sequences, suggesting that they are variants of the same functional protein. Homology searches showed no related genes in the databases.

Ribosomal protein genes were also highly expressed. Ribosomal protein gene $R p S 2$ was ranked at 5 th and other ribosomal protein genes $R p L 5$ and $R b L 36$ were in the top 20 highly expressed genes.

\section{Expression of housekeeping genes among tissues - EST map}

The gene expression pattern among libraries was visualized using a key word search in the BLASTX annotation and an Excel (Microsoft Corp.) macro program. This EST map appears to disclose the pattern of differential expression of highly expressed genes among tissues and stages. In the analyses of abundantly expressed genes in the previous section, abundance was judged from the direct number of ESTs in the libraries. In the EST map, a corrected value against the size of each library, the number of ESTs, was shown against 1,000 expressed genes. Although the ESTs that showed no key word in the highest score annotation text of BLASTX were not counted, the EST map provides a rough comparison of the expression pattern of a certain gene among tissues.

Figure 6a shows the EST map of actin-related genes. The word "actin" was searched in the gene annotation text of the top-ranked annotation in each gene and the appearance frequency was counted in each library. The actin gene showed high expression in the thorax and abdomen. The abdomen was also the high expression site of the actin gene. A quite similar pattern of gene expression to that of the actin gene was observed in the myosin gene, which was the 8th highly expressed gene in Table 2. Mucin-like gene is mostly expressed in the salivary glands (Fig 6b). The expression was also observed in the head and thorax sample, which contained the salivary glands. Figure $6 \mathrm{c}$ was drawn using the key word "trypsin". Trypsin or trypsin-like protease gene was expressed in the tissues in which the midgut was included. However, the number of ESTs (y axis) was small in this gene; the key word "trypsin" might not be appropriate for EST map of this gene. The EST map of vitellogenin or vitellogenin-like genes showed high expression of the gene in females (Fig. 6d).

\section{Highly expressed genes in each body part and developmental stage}

Abundantly expressed genes in each tissue or body part were examined. The top three contigs in the number of ESTs were selected using CLOBB analyses (Table 3). Most genes extracted in each library were so-called housekeeping genes. Some highly expressed genes showed no homology with the present data in the databases. An example of a body-part-specific gene was rhodopsin gene, which works for visualization and was the third in the number of ESTs in the female head (HA). The female thorax (TH) highly expressed actin and myosin; these genes appear to be expressed for the flight muscle, as described previously. Vitellogenin-like gene was the most abundant in the female abdomen $(\mathrm{AA}+\mathrm{AB})$. Vitellogenin is an egg yolk protein that is synthesized in the fat body before transportation into the eggs. Therefore, the high expression of this gene in female abdomen is reasonable. However, it was also found to be highly expressed in the salivary glands. Tissue specificity in gene expression was apparent and some specific genes were more abundantly recovered as ESTs than housekeeping genes. Functional analyses of these genes are important for elucidating spe- 

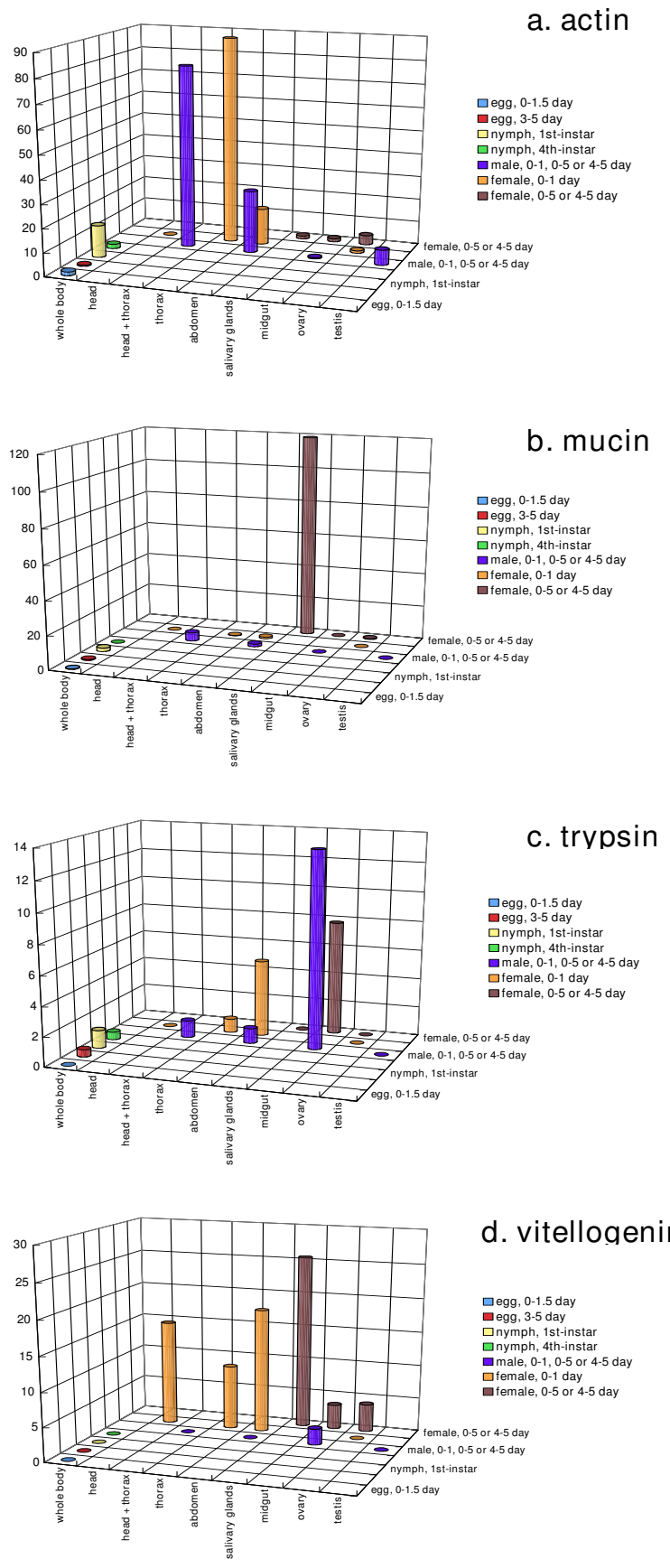

Figure 6

EST maps of highly expressed genes. The numbers of actin-, mucin-, trypsin-, and vitellogenin-related clones per I,000 ESTs are shown as three-dimensional bar graphs. The libraries of the salivary glands, head, thorax, and ovary were made from female adults; those of head+thorax and testis were made from male adults. The libraries of the abdomen and midgut were made from both male and female adults, and the library of the whole body from nymphs. The stages shown in the right axis are 0-I.5 day of eggs, 3-5 day of eggs, Ist instar nymphs, 4 th instar nymphs, adult males, $0-1$ day adult females and 0-5 day adult females toward the far side. 
Table 3: Top three genes highly expressed in each library

\begin{tabular}{|c|c|c|c|}
\hline Library & Representative clone & No. of EST & Annotation \\
\hline \multirow[t]{3}{*}{$A A+A B$} & $\mathrm{AA} 0013$ & 32 & gi|I54799937|dbj|BAF7535I.I| vitellogenin [Nilaparvata lugens] 352 le-95 \\
\hline & AA0016 & 16 & gi|90819992|gb|ABD98753.1| putative ADP/ATP translocase [Grap.. 26। 4e-72 \\
\hline & AAI 208 & 15 & gi|5 I 988476|gb|AAU20854.1| actin [Reticulitermes flavipes] $3389 \mathrm{e}-92$ \\
\hline \multirow[t]{5}{*}{$A C+A D$} & ACI062 & 17 & gi| I I0456520|gb|ABG747 I9.1| putative actin [Diaphorina citri] 42 I e- I I6 \\
\hline & $\mathrm{ACOI} 57$ & 11 & n.h. \\
\hline & AC0I55 & 10 & gi|50428904|gb|AAT77|52.I| arginine kinase [Periplaneta america.. 285 6e-76 \\
\hline & AC0302 & 10 & n.h. \\
\hline & AC0779 & 10 & gi|6067880 I|gb|AAX33735.I| MPA I3 allergen [Periplaneta americ.. 198 3e-49 \\
\hline \multirow[t]{6}{*}{ EA } & EA0377 & 38 & n.h. \\
\hline & EA0026 & 36 & n.h. \\
\hline & EAOIII & 33 & n.h. \\
\hline & EA0258 & 16 & gi|4504279|ref|NP_002098.I| H3 histone, family 3A [Homo sapiens] 263 le-68 \\
\hline & $\mathrm{EA0320}$ & 16 & gi| | 24805775|ref|XP_00 I 350534. I| eukaryotic translation initiatiati.. I I5 le-24 \\
\hline & EA033I & 16 & n.h. \\
\hline \multirow[t]{3}{*}{$\mathrm{EB}$} & EB0055 & 91 & n.h. \\
\hline & EBO302 & 71 & n.h. \\
\hline & EBOI69 & 54 & gi|9 |078856|ref|XP_972007.I| PREDICTED: similar to 60S riboso.. $16 \mathrm{I}$ le-38 \\
\hline \multirow[t]{3}{*}{$\mathrm{HA}$} & HA0029 & 54 & gi|70909775|emb|CAJI73।3.1| ribosomal protein L23Ae [Georissu.. 234 2e-60 \\
\hline & HAOI05 & 44 & n.h. \\
\hline & HA0046 & 32 & n.h. (homologous to rhodopsin) \\
\hline \multirow[t]{3}{*}{ HT } & НТ0003 & 223 & $\mathrm{gi}|156640546| \mathrm{gb}|\mathrm{ABU} 92560.1|$ actin [Monochamus alternatus] $17 \mid \mathrm{2e}-4 \mathrm{I}$ \\
\hline & НT0037 & 55 & gi|5668488 | |gb|AAW22542.1| myosin light chain [Gryllotalpa orien.. 273 5e-72 \\
\hline & HT0065 & 52 & gi| | 46229728|gb|ABQ I 2293.I| unknown [Antheraea pernyi nucleop.. 75 2e-12 \\
\hline \multirow[t]{3}{*}{ MA } & MAOOII & 371 & n.h. \\
\hline & MAOI60 & 158 & n.h. (homologous to trypsin-like protease) \\
\hline & MA0065 & 108 & n.h. \\
\hline \multirow[t]{3}{*}{ MB } & MB0025 & 184 & n.h. \\
\hline & MB0037 & 91 & n.h. (homologous to trypsin-like protease) \\
\hline & MB0028 & 59 & n.h. \\
\hline \multirow[t]{3}{*}{ NA } & NA00I3 & 130 & gi| | 58286709|ref|XP_00 I688 I I8.I| cuticular protein I40, RR-2 fa.. I0I 3e-20 \\
\hline & NA0I39 & 52 & gi|4656 |736|gb|AATO1073.I| putative muscle actin [Homalodisca c.. 545 e-I53 \\
\hline & NAI558 & 38 & gi| I58286709|ref|XP_00 I688I I8.I| cuticular protein I40, RR-2 fam.. 75 4e-12 \\
\hline \multirow[t]{3}{*}{ NB } & NB00I7 & 87 & 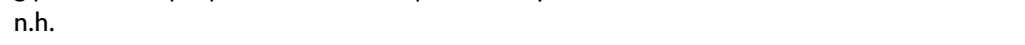 \\
\hline & NB0039 & 74 & gi|910915I0|ref|XP_969238.I| PREDICTED: similar to 60S riboso.. 373 e- 102 \\
\hline & NB0029 & 62 & gi|7090955I|emb|CA]I7I 97.I| ribosomal protein S3e [Scarabaeus.. 407 e- II2 \\
\hline \multirow[t]{3}{*}{ OA } & OA0030 & 13 & gi| I 1067| 482|gb|ABG8| 992.1| putative ribosomal protein S2 [Diap.. 164 2e-39 \\
\hline & OA0079 & 12 & $\begin{array}{l}\text { gi|| } 57767586 \mid \text { ref|XP_00I667273.I| Hypothetical protein CBGI604.. } 79 \text { 7e-I4 (ovary- } \\
\text { specifically expressed OC2756 in Table 4) }\end{array}$ \\
\hline & OA0009 & 11 & gi| $155966151 \mid$ gb|ABU41030.1| hypothetical protein [Lepeophtheirus.. 89 2e-16 \\
\hline \multirow[t]{3}{*}{$\mathrm{OB}+\mathrm{OC}$} & OB0024 & 210 & $\begin{array}{l}\text { gi||157767586|ref|XP_001667273.I| Hypothetical protein CBGI6043.. } 82 \text { 2e-I4 (ovary- } \\
\text { specifically expressed OC2756 in Table 4) }\end{array}$ \\
\hline & OB0360 & 118 & $\begin{array}{l}\text { gi| } 93102305 \mid \text { dbj|BAE } 93436.1 \mid \text { shematrin-4 [Pinctada fucata] } 97 \text { 7e- } 19 \text { (ovary-specifically } \\
\text { expressed OC0606 in Table 4) }\end{array}$ \\
\hline & OB0055 & 40 & gi|82470775|gb|AAL87229.3|AF480890_I metacaspase [Acantham.. 88 4e-16 \\
\hline \multirow[t]{4}{*}{ SG } & SG0085 & 490 & gi|46360 I58|gb|AAS88902.1] mucin-like protein [Laodelphax striat... 222 2e-56 \\
\hline & SG0019 & 108 & gi| I54799937|dbj|BAF7535I. I| vitellogenin [Nilaparvata lugens] 404 e- I I I \\
\hline & SG0023 & 107 & gi|6523547|emb|CAB62280.1| hydroxyproline-rich glycoprotein DZ-.. I 10 4e-23 \\
\hline & SG0076 & 107 & n.h. \\
\hline \multirow[t]{5}{*}{ TA } & TA0775 & 19 & n.h. (testis-specifically expressed NB3697 in Table 5) \\
\hline & TA0I86 & 15 & n.h. \\
\hline & TA0012 & 12 & n.h. (testis-specifically expressed ADI216 in Table 5) \\
\hline & TAOII8 & 12 & gi|66525050|ref|XP_625|45.I| PREDICTED: similar to tubulin, alph.. 285 le-75 \\
\hline & TA0428 & 12 & gi||I 07552 I0|ref|XP_393 I50.3| PREDICTED: similar to dumpy CG.. 7। 6e-II \\
\hline \multirow[t]{3}{*}{$\mathrm{TH}$} & TH0004 & 402 & gi|5 | 988476|gb|AAU20854. I| actin [Reticulitermes flavipes] 469 e- I 30 \\
\hline & TH0054 & 117 & gi| 17933672|ref|NP_524586.1| Myosin LC2 [Drosophila melanogas.. 22। 5e-56 \\
\hline & TH0020 & 62 & gi||154799937|dbj|BAF7535I.I| vitellogenin [Nilaparvata lugens] 395 e-108 \\
\hline
\end{tabular}

Representative clones are shown by an EST number in the cluster. "n.h." denotes no homology. HA0046 showed no homology, but other members of the cluster showed homology to rhodopsin. Other cluster members of MA0I60 and MB0037 showed homology to trypsin-like protease. 
cific features of BPH and probably homopteran or hemimetabolous insects.

\section{Genes specifically expressed in the gonads}

Reproductive organ-specifically expressed genes were sought. Insects showed various types of reproduction. Elucidation of the function of genes specifically expressed in the gonads is an interesting subject of research and an important topic for insect management through reproductive suppression or stimulation. Planthoppers, which are hemimetabolous insects, have telotrophic ovarioles, whereas holometabolous insects, such as fruit flies, mosquitoes, honeybees, and silkworms, have polytrophic ovarioles. Specific genes or specific function in the hemimetabolous insects are expected in the gonad-specifically expressed genes of $\mathrm{BPH}$.

In this species, the ovary starts to mature one or two days after adult emergence. Library $\mathrm{OA}$ is made from the immature ovary and its accessory glands of $0-1$ day old adults; $\mathrm{OB}$ and $\mathrm{OC}$ were made from mature ones of 4-5 days old. Libraries $\mathrm{AA}$ and $\mathrm{AB}$ were made from the female abdomen, which includes the female gonad. Therefore, the ESTs found only in the libraries $\mathrm{OA}, \mathrm{OB}, \mathrm{OC}, \mathrm{AA}$, and $\mathrm{AB}$ are candidate genes for female-gonad-specific expression. Table 4 shows the example of candidate ESTs of femalegonad-specifically expressed genes. These genes were selected by high-frequency expression in these five libraries and no expression in the other libraries. The ESTs that show expression in the libraries $\mathrm{OB}$ and $\mathrm{OC}$ and no expression in the library OA (e.g. EST clones AB0551, OB0998, OB1061, OC0638, OC0681) were probably expressed in the mature ovary and accessory glands. The restricted expression of these genes in the female gonad was confirmed by RT-PCR. Figure 7 shows the restricted gene expression of EST clone OC2756 in the female gonad and abdomen. In situ hybridization showed expression of this gene in the lateral oviduct (Fig. 8) as described previously. Further examination is necessary for characterizing these genes in ovarian development of $\mathrm{BPH}$.

Male-gonad-specifically expressed genes are presented in Table 5. Genes expressed in the testis and its accessory glands should be in the library TA and the libraries of the male abdomen $\mathrm{AC}$ and $\mathrm{AD}$, in which the male gonad is included. Since the male gonad starts to develop from the senior nymphal stage, the library NB might also include the gonad-specifically expressed genes. Therefore, the genes expressed in these libraries and not in other libraries were nominated. Candidate genes were brought into RTPCR examination and the genes confirmed to be expressed only in the male gonad are shown in Table 5. The results of RT-PCR and in situ hybridization of EST clone TA0721 are portrayed respectively in Fig. 7 and Fig.

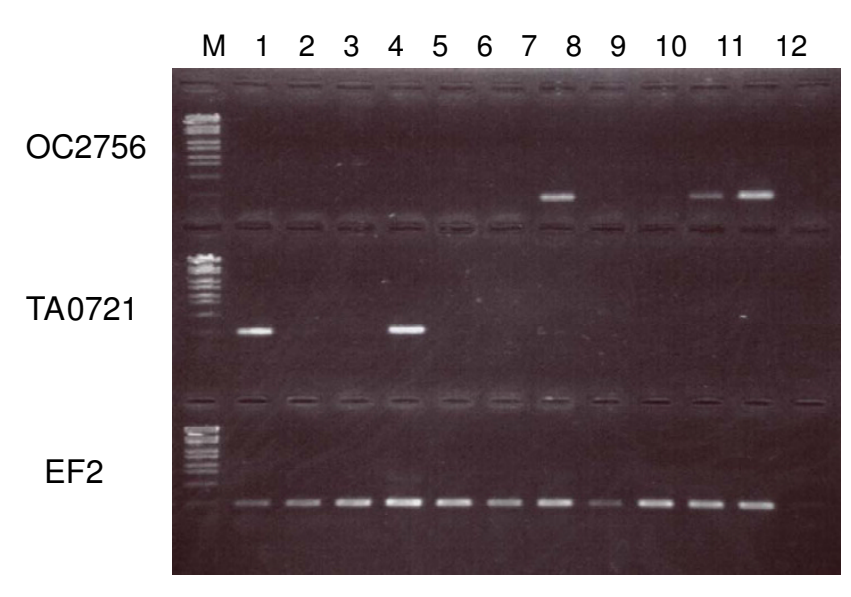

Figure 7

RT-PCR of EST clones OC2756 (AA0383) and TA072I showing specific expression in the gonads. EF2, elongation factor 2 gene (control); M, marker lambda-Eco TI 4 I digest; I, male abdomen; 2 , male head; 3 , male midgut; 4 , testis, 5 , 2nd instar nymph; 6, 4th instar nymph, 7, female abdomen; 8, female head; 9 , female midgut; 10, ovary of 0 -day-old adult; II, ovary of 4-day-old adult; 12, negative control of no template.

8. TA0721 was transcribed in an accessory gland of the testis.

The genes listed in Tables 4 and 5 are some gonad-specifically expressed genes. These genes were able to be selected because they expressed highly in the libraries of the gonad or the body part containing the gonad. Although this approach to extract tissue-specifically expressed genes is useful, it is not easy to obtain genes that are not actively expressed in the tissues.

\section{General feature of EST libraries and Gene ontology analysis}

Insects are a large group among animals and are quite divergent. Many ESTs of BPH showed no homology in the nucleotide and amino acid sequences. To examine the similarity level of the genes among insect species, we conducted homology searches using BLASTX against protein data of three insect species, Drosophila melanogaster, Anopheles gambiae, and Apis mellifera. All 37,122 ESTs were examined against each protein database, and were grouped by the e-value shown in the BLAST result (Fig. 9). Of ESTs, $35-40 \%$ showed homology with the proteins of the three insect species with $<e-30$, but $35-40 \%$ showed very little or no homology with the proteins of the three insects. Some genes showing 'no homology' or 'no-hitfound' might be those that are not translated into proteins. It is worth consideration that $\mathrm{BPH}$ is a hemimetabolous insect, which has no pupal stage, and the other 


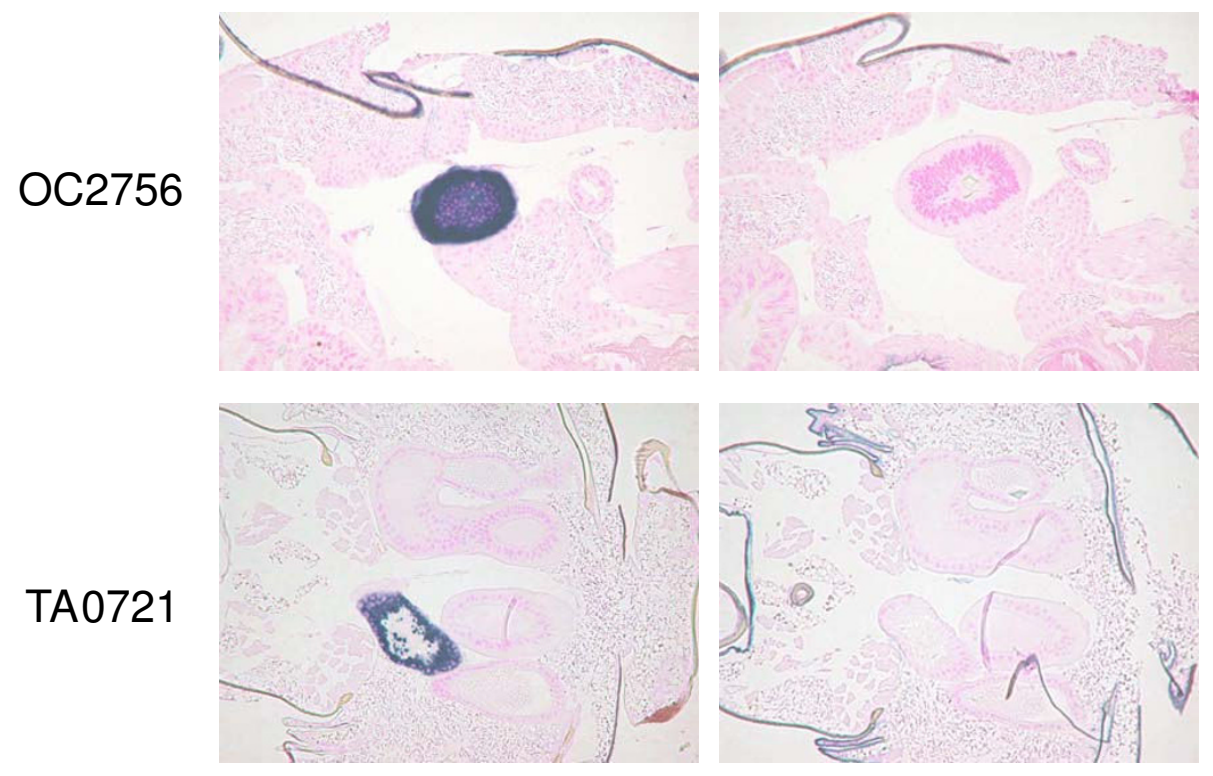

\section{Figure 8}

In situ hybridization of EST clone OC2756 (AA0383) in adult female and TA072I in adult male. Left, anti-sense probe; right, sense probe. Signals were observed in a part of the lateral oviduct (OC2756) and in an accessory gland of the testis (TA072I).

Table 4: Genes specifically expressed in the female gonad

\begin{tabular}{|c|c|c|c|c|c|c|c|c|}
\hline \multirow[t]{2}{*}{ Representative clone } & \multicolumn{7}{|c|}{ No. of ESTs in each library } & \multirow[t]{2}{*}{ Homology search BLASTX } \\
\hline & Total & OA & OB & OC & $\mathrm{AA}$ & $A B$ & Others & \\
\hline \multirow[t]{2}{*}{ AB055I } & 24 & 0 & 12 & 10 & I & I & 0 & gi|7657285|ref|NP_056624.I| keratin associated \\
\hline & 24 & 0 & 12 & 10 & I & I & 0 & protein 5-4 [Mus... 128 2e-28 \\
\hline \multirow{2}{*}{ ОВ0570 } & 10 & 0 & 3 & 5 & $\mathrm{I}$ & I & 0 & gi|7|06224|gb|AAF36090.I| flagelliform silk \\
\hline & 38 & 8 & 5 & 19 & 2 & 4 & 0 & protein [Nephila clavipes] $754 \mathrm{e}-12$ \\
\hline \multirow{2}{*}{ ОВ0998 } & 15 & 0 & 7 & 7 & 0 & I & 0 & n.h. \\
\hline & 14 & 0 & 7 & 7 & 0 & 0 & 0 & \\
\hline \multirow[t]{2}{*}{ OBI013 } & 27 & 2 & 9 & 16 & 0 & 0 & 0 & gi|245856 |8|ref|NP_724320.I| CG3 I626 \\
\hline & 26 & I & 9 & 16 & 0 & 0 & 0 & CG31626-PA, isoform A [Dros... I 36 le-30 \\
\hline \multirow[t]{2}{*}{ OBI06I } & 10 & 0 & 9 & 1 & 0 & 0 & 0 & n.h. \\
\hline & 10 & 0 & 9 & I & 0 & 0 & 0 & \\
\hline \multirow[t]{2}{*}{ OC0606 } & 122 & 8 & 30 & 76 & 5 & 3 & 0 & gi|93102305|dbj|BAE93436.I| shematrin-4 \\
\hline & 121 & 9 & 30 & 78 & I & 3 & 0 & [Pinctada fucata] $977 \mathrm{e}-19$ \\
\hline \multirow[t]{2}{*}{ OC0638 } & 20 & 0 & 9 & 11 & 0 & 0 & 0 & gi| | 49258 I 54|ref|XP_00 | 480786. I| PREDICTED \\
\hline & 20 & 0 & 9 & 11 & 0 & 0 & 0 & hypothetical protein... $1592 \mathrm{e}-37$ \\
\hline \multirow[t]{2}{*}{ OC068I } & 35 & 0 & 17 & 18 & 0 & 0 & 0 & gi|8288076I|ref|XP_901600.I| PREDICTED: \\
\hline & 35 & 0 & 17 & 18 & 0 & 0 & 0 & hypothetical protein LOC... $1612 \mathrm{e}-38$ \\
\hline \multirow[t]{2}{*}{ OCIOI4 } & 42 & 6 & 4 & 26 & 4 & 2 & 0 & gi| $155966|43| g b|A B U 4| 026.1 \mid$ hypothetical \\
\hline & 38 & 6 & 4 & 26 & 0 & 2 & 0 & protein [Lepeophtheirus... $832 \mathrm{e}-14$ \\
\hline \multirow[t]{2}{*}{ OCI083 } & 27 & 2 & 7 & 18 & 0 & 0 & 0 & gi|72547036|ref|XP_843163.1| proteophospho- \\
\hline & 26 & 1 & 7 & 18 & 0 & 0 & 0 & glycan 5 [Leishmania ma.. $724 \mathrm{e}-13$ \\
\hline \multirow[t]{2}{*}{ OC2756 } & 119 & 6 & 26 & 85 & 0 & 2 & 0 & gi|| 57767586|ref|XP_001667273.I| Hypothetical \\
\hline & 228 & 12 & 55 & 155 & 3 & 3 & 0 & protein CBG I 6043 [Caeno... 79 9e-14 \\
\hline
\end{tabular}

The numbers of ESTs detected in the five libraries related with the ovary and its accessory glands are shown. $O A, O B$ and $O C$ are the libraries from the female gonad and $A A$ and $A B$ are those from the female abdomen. The upper line is the number of cluster members in each library using the clustering algorithm CBP; the lower line those using CLOBB. "n.h." denotes no homology. The category for 'no homology' is described in Gene annotation in Methods. 
Table 5: Genes specifically expressed in the male gonad

\begin{tabular}{|c|c|c|c|c|c|c|c|}
\hline \multirow[t]{2}{*}{ Representative clone } & \multicolumn{6}{|c|}{ No. of ESTs in each library } & \multirow[t]{2}{*}{ Homology search BLASTX } \\
\hline & Total & TA & $A C$ & $A D$ & NB & Others & \\
\hline \multirow[t]{2}{*}{ AC0657 } & 11 & 7 & 4 & 0 & 0 & 0 & n.h. \\
\hline & 11 & 7 & 4 & 0 & 0 & 0 & \\
\hline \multirow[t]{2}{*}{ AC0743 } & 6 & 4 & I & I & 0 & 0 & gi|| 57 I33853|ref|XP_00166304I.I| hypothetical \\
\hline & 9 & 5 & I & 3 & 0 & 0 & protein AaeL_AAEL02908.. 72 2e-II \\
\hline \multirow[t]{2}{*}{ AC0825 } & 10 & 6 & 3 & 1 & 0 & 0 & gi|| | 4629259|ref|XP_52|4|0.2| PREDICTED: \\
\hline & 10 & 6 & 3 & I & 0 & 0 & hypothetical protein $[\mathrm{Pan} . .1002 \mathrm{e}-19$ \\
\hline \multirow[t]{2}{*}{$A D 1216$} & 17 & 12 & 2 & 3 & 0 & 0 & n.h. \\
\hline & 17 & 12 & 2 & 3 & 0 & 0 & \\
\hline \multirow[t]{2}{*}{ NB2328 } & 17 & 11 & 2 & 2 & 2 & 0 & n.h. \\
\hline & 17 & 11 & 2 & 2 & 2 & 0 & \\
\hline \multirow[t]{2}{*}{ NB3697 } & 26 & 19 & 1 & 3 & 3 & 0 & n.h. \\
\hline & 26 & 19 & I & 3 & 3 & 0 & \\
\hline \multirow[t]{2}{*}{ NB5623 } & 9 & 4 & 2 & 0 & 3 & 0 & n.h. \\
\hline & 19 & 11 & 2 & 2 & 4 & 0 & \\
\hline \multirow[t]{2}{*}{ TA0293 } & 11 & 10 & 0 & 1 & 0 & 0 & gi|| 56 | 3784|ref|NP_242087.I| hypothetical \\
\hline & II & 10 & 0 & I & 0 & 0 & protein $\mathrm{BH} 221$ [Bacillus.. 72 3e-II \\
\hline \multirow[t]{2}{*}{ TA0428 } & 6 & 6 & 0 & 0 & 0 & 0 & gi| I I07552 I0|ref|XP_393 I50.3| PREDICTED: \\
\hline & 17 & 12 & 3 & 2 & 0 & 0 & similar to dumpy CG3319.. 71 6e-1I \\
\hline \multirow[t]{2}{*}{ TA0528 } & 12 & 10 & 0 & 2 & 0 & 0 & n.h. \\
\hline & 11 & 9 & 0 & 2 & 0 & 0 & \\
\hline \multirow[t]{2}{*}{ TA072I } & 20 & 11 & I & 8 & 0 & 0 & n.h. \\
\hline & 20 & II & 1 & 8 & 0 & 0 & \\
\hline \multirow[t]{2}{*}{ TA1050 } & 4 & 2 & 0 & 2 & 0 & 0 & gi|9।08442।|ref|XP_9682।5.I| PREDICTED: \\
\hline & 14 & 9 & 0 & 5 & 0 & 0 & similar to CG64|4-PA [Tribo.. I I6 le-24 \\
\hline \multirow[t]{2}{*}{ TA1095 } & 12 & 8 & 2 & 2 & 0 & 0 & n.h. \\
\hline & 12 & 8 & 2 & 2 & 0 & 0 & \\
\hline
\end{tabular}

The numbers of ESTs detected in the four libraries related with the testis and its accessory glands are shown. TA is the library of the male gonad, $A C$ and $A D$ are those from the male abdomen, and NB is that of 4th instar nymphs. The upper line is the cluster member in each library using the clustering algorithm CBP; the lower line those using CLOBB. "n.h." denotes no homology. The category for 'no homology' is described in Gene annotation in Methods.

three species are holometabolous ones. This difference might affect the low homology between them.

\section{Conclusion}

The most feared pest of rice plants is BPH. The EST database constructed in this study and described herein will be useful for the molecular studies of BPH. BPH shows resistance against various insecticides. Insecticide resistance mechanisms are considered to be attributable to the high enzyme activities, which metabolize the compounds quickly $[3,35,37]$. They are also partially attributable to the mutations in the genome sequences in the target molecules, which cause insensitivity to the chemicals $[4,38]$. Gene sequences of the metabolic enzymes and insecticide-target molecules might be obtained from the database. The EST database is also useful for identifying potential target genes for developing novel insecticides against planthoppers [39]. The database will also be useful for finding important functional molecules [34,40,41] as well as for searching for hemipterous insect-specific or tissue-specific genes. Genomic sequence data are unavailable in Nilaparvata lugens. Therefore, EST data will also be used for identification of proteins in proteomic studies [42].

Further determination of complete cDNA sequences is underway. Microarrays produced based on the EST data and some additional sequences from ongoing full-length cDNA analyses are expected to become powerful tools for gene expression analyses. The microarray analyses will be applied for elucidation of mechanism of wing dimorphism in planthoppers. Long or short wings are induced by environmental stimuli during nymphs and the response is different between sexes. A recently developed molecular sexing method in BPH [43], which enable to distinguish sexes in nymphal stages, will contribute to studying wing dimorphism in BPH together with the microarrays. Gene expression profiles of BPH that attack various resistant varieties of rice plants will be useful for elucidating the molecular mechanism of rice plant resistance and planthopper virulence against resistant rice plants. Expressed genes related to plant-sucking and nutrient digestion are also important targets in $\mathrm{BPH}$ physiological and biochemical studies. In addition, results reveal 


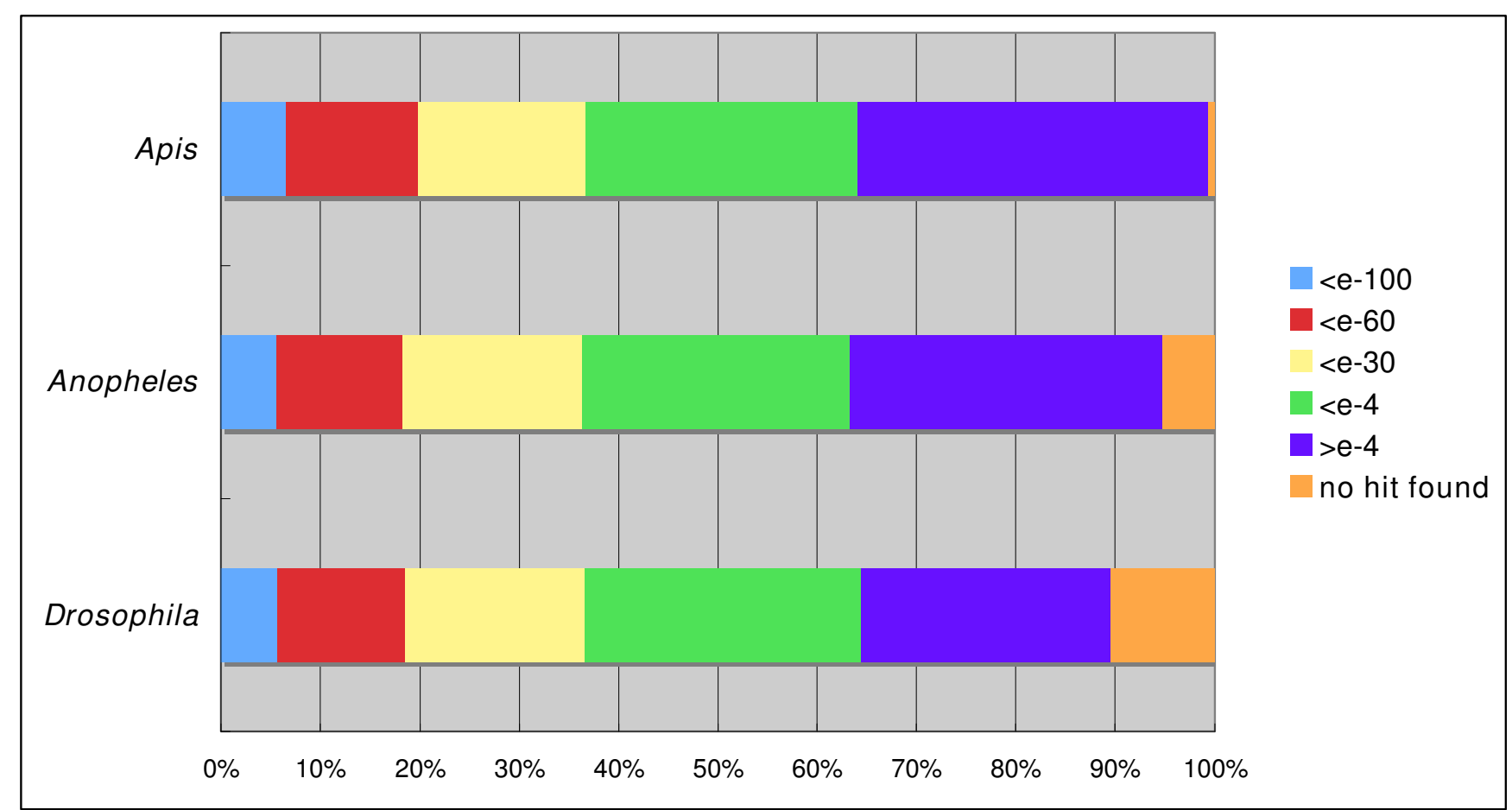

\section{Figure 9}

Homology of planthopper ESTs with three insect species by BLASTX. All 37, I 22 ESTs were examined against protein databases of Apis mellifera, Anopheles gambiae, and Drosophila melanogaster. The ratios of the EST clones are shown based on the evalue in the annotation description of BLASTX.

that RNA interference (RNAi) is quite effective in BPH (data in preparation). This important agricultural pest might also be used as a hemimetabolous model insect in the near future as well as several aphid species. The continued accumulation of information related to Nilaparvata lugens can promote efforts to control other economically important rice planthopper species: Sogatella furcifera and Laodelphax striatellus.

\section{Methods}

\section{Insects and RNA preparation}

Nilaparvata lugens (Hemiptera, Delphacidae) were collected in Izumo, Shimane Prefecture, Japan in 1987. This Izumo strain was reared with rice seedlings at $26^{\circ} \mathrm{C}$ under a long day photoperiod of $16 \mathrm{~h}$ of light and $8 \mathrm{~h}$ of dark in plastic boxes as a stock population.

Egg samples were collected from 5\% sucrose solution into which mature females were allowed to lay eggs through a proprietary membrane (Parafilm M; American National Can Group Inc., Chicago). Nymphs were reared in glass bottles (ca. $18 \mathrm{~cm}$ high; $9 \mathrm{~cm}$ diameter) containing rice seedlings. Stage-specific samples were prepared from those reared in a test tube (ca. $13 \mathrm{~cm}$ high; $16 \mathrm{~mm}$ diameter) with rice seedlings. Approximately 500 insects were used for lambda ZAP libraries and ca. 50 for pGEM plasmid libraries. More than 1,000 individuals were used for egg and young nymphal libraries. Planthopper tissues were dissected under a binocular. The planthoppers were dipped in $70 \%$ ethanol for several seconds and washed in $0.85 \% \mathrm{NaCl}$ solution. They were then dissected in a droplet of saline solution with fine forceps and the tissues were dipped into the extraction buffer of QuickPrep Micro mRNA Purification Kit (Amersham Biosciences UK Ltd., England) and polyA+ mRNA was purified. Some large samples were homogenized in the extraction buffer in a microfuge tube using a small pestle.

\section{cDNA Libraries}

Two libraries were made for tissues. One was that made with lambda-ZAPII (Stratagene, USA). The cDNAs were inserted unidirectionally into the lambda ZAP II vector and in vivo mass excision of the pBluescript SK phagemid from the ZAP vector was performed to obtain bacterial colonies. The other is a plasmid library of amplified cDNA. First strand cDNA was synthesized using an oligodT primer (5'-TGTGTCTAGAGGATCCGTACCCAGC(T) $\left.{ }_{30} \mathrm{VN}-3^{\prime}\right)$ along with SMART II oligonucleotide (5'-AAGCAGTGGTAACAACGCAGAGTACGCGGG-3') in a SMART RACE cDNA amplification Kit (Clontech Labo- 
ratories Inc., USA). Amplification of cDNA was performed with SMART technology using the nested universal primer (NUP) (5'-AAGCAGTGGTAACAACGCAGAGT-3') in the kit and 3'-PCR primer (5'-TGTGTCTAGAGGATCCGTACCCAGC-3'). The amplified DNA was purified with sepharose CL-2B (Amersham Biosciences AB, Sweden) in a mini-column $(60 \times 7.5 \mathrm{~mm}$; about $2.5 \mathrm{ml})$ to eliminate small sized DNA and ligated into pGEM-T (Promega Corp., USA) by TA-cloning. Usual blue-white selection of the bacterial colonies was done on the LB agar plates.

\section{Sequencing}

Sequencing templates were prepared by colony PCR from bacterial colonies on the agar plate using M13-20 and reverse primers. The amplified products were purified with a spin column of sephacryl S-300 HR (Amersham Biosciences $\mathrm{AB}$, Sweden). The sequencing reaction was performed using Big Dye Terminator v3.0 or v3.1 (Applied Biosystems, USA) with a DNA Sequence System (model 377, PE Applied Biosystems) or a DNA analyzer (model 3700, PE Applied Biosystems). The sequencing primers were SK primer 5'-CGCTCTAGAACTAGTGGATC3 ' for the clones in pBluescript, and NUP primer for the clones in pGEM. These primers enable us to read the sequence of the positive strand.

\section{Sequence Processing}

All sequences generated from the sequencers were first processed manually to remove vector sequences and improper regions of the sequence. In order to delete contaminants and unnecessary sequences in the ESTs, a local BLAST search using the BLASTALL program downloaded from NCBI [44] was performed with a desktop computer (Mac OSX; Apple Computer Inc., USA). Planthopper EST database file was made using Formatdb program and BLASTN searches were performed. The following genome or gene sequences were eliminated: cloning vectors (lambda ZAP II and pGEM), Escherichia coli genome, planthopper viruses [NLRV, NC_003652-NC_003661; NLCXV, AB183424, himetobi $\mathrm{P}$ virus or Hi-PV, AB183472]; planthopper mitochondrial genome; and planthopper partial ribosomal rRNA gene including retrotransposon R2. The EST sequences showing a homology E-value of $<1.0 \times 10^{-20}$ to the query sequences were eliminated from the EST libraries. The ESTs were further tested for vector sequence contamination using NCBI VecScreen; ESTs of less than 300 bp were also discarded.

\section{EST Assembly}

The ESTs were grouped into clusters using two clustering algorithms. One is the Cluster on the basis of BLAST similarity (CLOBB) [25]. The parameters used in this Perl script were $95 \%$ identity and 50 bp coverage. The other is the method of combined BLAST and PhredPhrap (CBP) [26]. In this method, the identity value and coverage length were started from $97 \%$ and $90 \mathrm{bp}$, respectively; the coverage length value and identity value were raised to attain the final consensus result. The contig members were tested for a 95\% identity and $90 \%$ covering ratio after the clustering process.

\section{Gene annotation}

Genes were identified by sequence similarity comparison against NCBI RefSec using BLASTX. We used the -F F option for examining low complexity sequences. The degree of sequence homology was based on the following standards. 'High homology' is given to the EST clones which fulfilled the following three conditions: E-value is $1 \mathrm{e}-10$ or less, amino acid homologous regions were more than $99 \mathrm{bp}$, and the identity is $30 \%$ or more. 'Low homology' signifies that the E-value is $1 \mathrm{e}-10$ or less, but the two other conditions described for the high homology categories are not fulfilled. 'No homology' fulfilled no conditions.

\section{EST map}

BLAST annotation text was used to visualize the expression pattern of housekeeping genes among libraries. The BLASTX searches were performed in 37,122 ESTs and the top annotation description for each EST was selected in the text-base in individual libraries. A key word search was done through the text of all selected annotation descriptions in each library, and the hits was counted. The number of hits was considered as the number of cDNA related to the key word. The numbers of ESTs analyzed differ among libraries. For that reason, the number of hits was normalized by conversion into the number per 1,000 ESTs (number of hits/number of EST in each library $x$ 1,000 ). The normalized value (number of hits per 1,000 ESTs) was visualized using three-dimensional bar charts produced using Excel software (Microsoft Corp., USA).

\section{BLASTX analysis against insect amino acid databases}

BLASTX analyses were performed for all ESTs as query data against amino acid databases of Drosophila melanogaster, Anopheles gambiae, and Apis mellifera. Protein sequence databases of these insect species were obtained from NCBI. Database sizes of D. melanogaster, A. gambiae, and A. mellifera, were, respectively, 76,066, 33,024, and 9,965 proteins or amino acid sequences. The BLAST command used was "blastall -p blastx -F F -v 1 -b 1 -m 8". The BLAST results were divided into six groups according to the $e$ value, $<e-100,<e-60,<e-30,<e-4,>e-4$, and no hit found.

\section{RT-PCR}

A highly expressed gene, MB3851, and gonad-specifically expressed genes were examined for transcriptional specificity in stages or tissues. Messenger RNA of desired stages or tissues were extracted using an RNeasy mini kit (Qiagen Inc., USA); cDNA was synthesized using the ExScript RT 
Table 6: Primer sequences used for RT-PCR

\begin{tabular}{|c|c|c|c|}
\hline Representative clone & & Primer sequence & Product size (bp) \\
\hline \multicolumn{4}{|l|}{ Highly expressed in $\mathrm{BPH}$} \\
\hline \multirow[t]{2}{*}{ MB385 I } & forward & GGCGTGTTGGTGTTGCTTCA & 515 \\
\hline & reverse & GCTTAGCAAATCCTGGGACA & \\
\hline \multicolumn{4}{|c|}{ Female gonad-specifically expressed } \\
\hline \multirow[t]{2}{*}{ AB055I } & forward & AATCATCGCTGCTTTCCTCGCC & 437 \\
\hline & reverse & GGGAGCAAGGAGAGGCTATTAC & \\
\hline \multirow[t]{2}{*}{ OB0570 } & forward & GGGACACAGACTTAACTTGGCG & 505 \\
\hline & reverse & AGCAACTCTTGCTCCATAGT & \\
\hline \multirow[t]{2}{*}{ OB0998 } & forward & TCCCAAAGTCGATGGCCGAATC & 529 \\
\hline & reverse & TGGTACTGACTGATCGTTCC & \\
\hline \multirow[t]{2}{*}{ OBI0I3 } & forward & GACGGAGCAACCGTACATAT & 486 \\
\hline & reverse & CGGTGAAGTAGATGGTCTCA & \\
\hline \multirow{2}{*}{ OB 1061} & forward & CATCAGCCCTGTGACGATAGAG & 602 \\
\hline & reverse & TCTGCACTCGCTGCTGTTCCAT & \\
\hline \multirow[t]{2}{*}{ OC0606 } & forward & CTGTGATCTCAAGCTCAGCCTG & 498 \\
\hline & reverse & CACCAGCATGACCTTGGAGTAC & \\
\hline \multirow[t]{2}{*}{ OC0638 } & forward & GTCTGTGCCCTTTGCGCCAT & 504 \\
\hline & reverse & GCATGGCTGATGGCAGACTG & \\
\hline \multirow[t]{2}{*}{ OC068I } & forward & GTAAAATGGCCGCCAAGTCACT & 435 \\
\hline & reverse & GAATGGAGAGGTGTGTTGCA & \\
\hline \multirow[t]{2}{*}{ OCIOI4 } & forward & CGTTGTTGCTGCCTTGGCACTA & 480 \\
\hline & reverse & CCTGGATTTGCCTAAGCTGCAA & \\
\hline \multirow[t]{2}{*}{ OCI083 } & forward & CATCCTGTGGATGCGGATACTC & 512 \\
\hline & reverse & GACTAGTAAAGCACAGATCG & \\
\hline \multirow[t]{2}{*}{ OC2756 } & forward & AGTGATCACAAGCTCTGCCTG & 382 \\
\hline & reverse & TATGCCACACAGCCAACACCAG & \\
\hline \multicolumn{4}{|l|}{ Male gonad-specifically expressed } \\
\hline \multirow[t]{2}{*}{ AC0657 } & forward & CGAGCTCTGTGTTGCTGAAG & 575 \\
\hline & reverse & CAGCAGGAGTTAAAACATGGG & \\
\hline \multirow[t]{2}{*}{ AC0743 } & forward & САССAACTCAACACTCCAC & 525 \\
\hline & reverse & TTACTTCGGCCACACGGCTC & \\
\hline \multirow[t]{2}{*}{ AC0825 } & forward & GCGACTGGTGCAAAGTAGCA & 610 \\
\hline & reverse & TCTTGACTCAGCTTCCCATC & \\
\hline \multirow[t]{2}{*}{$A D 1216$} & forward & CTTCATTGTGGCTGTTGCAAG & 444 \\
\hline & reverse & TCAGGGTATAGTGACCTTCC & \\
\hline NB2328 & forward & ССTCAGTACACAGTGAAACTC & 480 \\
\hline & reverse & GCTCTTCACAGGGATCCACA & \\
\hline NB3697 & forward & GGCAGAATCAGTCGAAGATC & 435 \\
\hline & reverse & GCGCCACATTTTGGAATGGG & \\
\hline NB5623 & forward & AGAACCAAACCCAAACAGGC & 416 \\
\hline & reverse & GTTACACGGATACAAACCCTG & \\
\hline TA0293 & forward & ACCATGCAGCAGAGGGAATC & 542 \\
\hline & reverse & GGATGGGTGACCATGGAGTC & \\
\hline TA0428 & forward & ССАТСTССTGAAACTGTAGG & 464 \\
\hline & reverse & AGGCAGTTCAAGTGGCTCTC & \\
\hline TA0528 & forward & CCAAAACTCCTACGGTACCG & 502 \\
\hline & reverse & TTTTTCGCAGGGGTCGGTGC & \\
\hline TA072I & forward & САСТСATCTCCAGTGATACC & 452 \\
\hline & reverse & CTGGTGCTAATGTTGGAGCG & \\
\hline TAI050 & forward & TCATTTTCCCGATGGCAAGC & 527 \\
\hline & reverse & TTTCGACGGCACGCTTCTCC & \\
\hline TAI095 & forward & CCAGAGATCCTGCAGAGACA & 545 \\
\hline & reverse & GCCTTAGTGTAACACTATTCCC & \\
\hline Control PCR primer for templa & & & \\
\hline NL_EF2 & forward & GAAGTTCAGTGTGTCGCCTG & 420 \\
\hline & reverse & TCTCCCAGATATCTGGCTCT & \\
\hline
\end{tabular}


reagent Kit (Takara Bio Inc., Japan) with oligo-dT primer or random 9-mer primers. Thermal conditions for RT-PCR were usually $95^{\circ} \mathrm{C}$ for $10 \mathrm{sec}$, followed by 30-35 cycles of $95^{\circ} \mathrm{C}$ for $30 \mathrm{sec}, 52^{\circ} \mathrm{C}$ for $30 \mathrm{sec}$, and $72^{\circ} \mathrm{C}$ for $1 \mathrm{~min}$. Primers were designed based on contig sequences generated from ESTs of the same cluster (Table 6). The PCR products and their sizes were examined using agarose gel electrophoresis followed by ethidium bromide staining. The prepared cDNAs were tested for validity of template preparation using a primer pair of the elongation factor 2 gene of $\mathrm{BPH}$.

\section{In situ hybridization}

Planthopper specimens for in situ hybridization were fixed with 5\% formaldehyde including $0.5 \%$ picric acid and embedded in paraffin wax. The tissue sections were de-waxed with xylene and re-hydrated through an ethanol series. The sections were fixed with $4 \%$ paraformaldehyde in phosphate-buffered saline (PBS) and treated with 10 $\mathrm{mg} / \mathrm{ml}$ Proteinase $\mathrm{K}$ for $30 \mathrm{~min}$ at $37^{\circ} \mathrm{C}$. After re-fixing with the $4 \%$ paraformaldehyde, they were acetylated by incubation in $0.1 \mathrm{M}$ triethanolamine- $\mathrm{HCl}, \mathrm{pH} 8.0,0.25 \%$ acetic anhydride for $10 \mathrm{~min}$. After dehydration through an ethanol series, hybridization was performed with probes at concentrations of $100 \mathrm{ng} / \mathrm{ml}$ in the Probe Diluent (Genostaff, Tokyo) at $60^{\circ} \mathrm{C}$ for $16 \mathrm{hr}$. About $350 \mathrm{bp}$ fragment DNA were made using PCR, and digoxigenin (DIG)labeled sense and anti-sense probes were produced by DIG RNA Labeling Kit (Roche Diagnostics Corporation). After hybridization, they were washed in $5 \times \mathrm{SSC}$, at $60^{\circ} \mathrm{C}$ for $20 \mathrm{~min}$ and then in $50 \%$ formamide, $2 \times \mathrm{SSC}$ at $60^{\circ} \mathrm{C}$ for $20 \mathrm{~min}$, followed by RNase treatment for $30 \mathrm{~min}$ at $37^{\circ} \mathrm{C}$. The sections were then washed twice with $2 \times \mathrm{SSC}$, $0.2 \times$ SSC, and $0.1 \%$ Tween in Tris buffered saline (TBST). After treatment with $0.5 \%$ blocking agent (Roche) in TBST, the sections were incubated with anti-DIG AP conjugate (Roche) diluted 1:1000 with TBS for $2 \mathrm{hr}$. Coloring reactions were performed with $\mathrm{BM}$ purple AP substrate (Roche). The sections were counterstained with Kernechtrot stain solution (Mutoh Chemical Co., Tokyo).

\section{Abbreviations}

BLAST: Basic local alignment search tool; BPH: The brown planthopper; CBP: Method of combined BLAST and PhredPhrap; CLOBB: cluster on the basis of BLAST similarity; EST: expressed sequence tags; GO: gene ontology; Hi-PV: himetobi P virus; NCBI: National Center for Biotechnology Information; NLCXV: Nilaparvata lugens commensal X viurs; NLRV: Nilaparvata lugens reovirus; RT-PCR: reverse transcriptase-polymerase chain reaction; SMART: switching mechanism at 5' end of the RNA transcript.

\section{Authors' contributions}

HN participated in the conception of the project, experimental design, sample preparation, data analyses, and manuscript preparation. SK studied gonad-specifically expressed EST and conducted RT-PCR. YK performed plasmid library construction, EST sequencing and manual processing of the sequence data. KM constructed phage libraries. QZ participated in sequencing and data processing of some clones. SF performed EST annotation and constructed a web site for the EST database. MS performed EST clustering by CBP and constructed EST map. KM provided overall knowledge related to the EST project. All authors read and approved the final manuscript.

\section{Acknowledgements}

We thank Junko Shiba, Masako Ebihara, Yoshihiko Tamano, Kayoko Tomita, Krishnakumar Sreelekha, Ayako Matsumoto, Baoxiu Qi-Walsh, and Yuki Sato for technical assistance of sequencing, Keiko Watanabe for rearing planthoppers, Makoto Hattori for dissecting the salivary glands, and Yoshiaki Nagamura for invaluable advice. This work was supported by the Project for Insect Technology (2002-2006) and the Integrated Research Project for Plant, Insect and Animal Using Genome Technology (2007-) of the Ministry of Agriculture, Forestry, and Fisheries of Japan.

\section{References}

I. Hibino H: Biology and epidemiology of rice viruses. Annu Rev Phytopathol 1996, 34:249-274.

2. Heinrichs EA: Impact of insecticides on the resistance and resurgence of rice planthoppers. In Planthoppers: Their Ecology and Management Edited by: Denno RF, Perfect TJ. New York: Chapman \& Hall, Inc; 1994:57I-598.

3. Vontas JG, Small GJ, Hemingway J: Comparison of esterase gene amplification, gene expression and esterase activity in insecticide susceptible and resistant strains of the brown planthopper, Nilaparvata lugens (Stal). Insect Mol Biol 2000, 9:655-660.

4. Liu Z, Han Z: Fitness costs of laboratory-selected imidacloprid resistance in the brown planthopper, Nilaparvata lugens Stal. Pest Management science 2006, 62:279-282.

5. Gallagher KD, Kenmore PE, Sogawa K: Judicial use of insecticides deter planthopper outbreaks and extend the life of resistant varieties in Southeast Asian rice. In Planthoppers: Their Ecology and Management Edited by: Denno RF, Perfect TJ. New York: Chapman \& Hall, Inc; 1994:599-6I4.

6. $\quad W u J, X u J$, Yuan S, Liu J, Jian Y, Xu J: Pesticide-induced susceptibility of rice to brown planthopper Nilaparvata lugens. Entomol Exp Appl 200I, 100: I 19-126.

7. Tanaka K: Quantitative genetic analysis of biotypes of the brown planthopper Nilaparvata lugens: heritability of virulence to resistant rice varieties. Entomol Exp Appl 1999, 90:279-287.

8. Kim SM, Sohn JK: Identification of a rice gene (Bph I) conferring resistance to brown planthopper (Nilaparvata lugens Stal) using STS markers. Molecules and cells 2005, 20:30-34.

9. Jena KK, Jeung JU, Lee JH, Choi HC, Brar DS: High-resolution mapping of a new brown planthopper (BPH) resistance gene, BphI8(t), and marker-assisted selection for BPH resistance in rice (Oryza sativa L.). TAG Theor Appl Genetics 2006, I I 2:288-297.

10. Chen JW, Wang L, Pang XF, Pan QH: Genetic analysis and fine mapping of a rice brown planthopper (Nilaparvata lugens Stal) resistance gene bph 19(t). Mol Genet Genomics 2006, 275:32I-329.

II. Kang L, Chen X, Zhou Y, Liu B, Zheng W, Li R, Wang J, Yu J: The analysis of large-scale gene expression correlated to the phase changes of the migratory locust. Proc Natl Acad Sci USA 2004, I0I:176II-176I5. 
12. Hunter WB, Dang PM, Bausher MG, Chaparro JX, McKendree W, Shatters RG Jr, McKenzie CL, Sinisterra XH: Aphid biology: expressed genes from alate Toxoptera citricida, the brown citrus aphid. Insect Science 2003, 3:23.

13. Tagu D, Prunier-Leterme N, Legeai F, Gauthier JP, Duclert A, Sabater-Munoz B, Bonhomme J, Simon JC: Annotated expressed sequence tags for studies of the regulation of reproductive modes in aphids. Insect Biochem Mol Biol 2004, 34:809-822.

14. Sabater-Munoz B, Legeai F, Rispe C, Bonhomme J, Dearden P, Dossat C, Duclert A, Gauthier JP, Ducray DG, Hunter W, et al.: Large-scale gene discovery in the pea aphid Acyrthosiphon pisum (Hemiptera). Genome Biology 2006, 7:R21.

15. Leshkowitz D, Gazit S, Reuveni E, Ghanim M, Czosnek H, McKenzie C, Shatters RL Jr, Brown JK: Whitefly (Bemisia tabaci) genome project: analysis of sequenced clones from egg, instar, and adult (viruliferous and non-viruliferous) $c D N A$ libraries. $B M C$ genomics 2006, 7:79.

16. Negre V, Hotelier T, Volkoff AN, Gimenez S, Cousserans F, Mita K, Sabau X, Rocher J, Lopez-Ferber M, d'Alencon E, et al.: SPODOBASE: an EST database for the lepidopteran crop pest Spodoptera. BMC Bioinformatics 2006, 7:322.

17. Allen ML: Expressed sequenced tags from Lygus lineolaris (Hemiptera: Miridae), the tarnished plant bug. Genet Mol Res 2007, 6:206-2/3.

18. Ramsey JS, Wilson AC, de Vos M, Sun Q, Tamborindeguy C, Winfield A, Malloch G, Smith DM, Fenton B, Gray SM, et al.: Genomic resources for Myzus persicae: EST sequencing, SNP identification, and microarray design. BMC Genomics 2007, 8:423.

19. UNKA (BPH) EST [http://bphest.dna.affrc.go.jp/]

20. Noda $H$, Ishikawa $K$, Hibino $H$, Omura $T$ : A reovirus in the brown planthopper, Nilaparvata lugens. J Gen Virol I99I, 72:2425-2430.

21. Nakashima N, Koizumi M, Watanabe H, Noda H: Complete nucleotide sequence of the Nilaparvata lugens reovirus: a putative member of the genus Fijivirus. J Gen Virol 1996, 77:139-| 46.

22. Nakashima N, Kawahara N, Omura T, Noda H: Characterization of a novel satellite virus and a strain of Himetobi $P$ virus (Dicistroviridae) from the brown planthopper, Nilaparvata lugens. J Invertebr Pathol 2006, $91: 53-56$

23. Toriyama S, Guy PL, Fuji S, Takahashi M: Characterization of a new picorna-like virus, himetobi $\mathbf{P}$ virus, in planthoppers. Gen Virol 1992, 73:1021-1023.

24. Suzuki Y, Toriyama S, Matsuda I, Kojima M: Detection of a picornalike virus, Himetobi $\mathbf{P}$ virus, in organs and tissues of Laodelphax striatellus by immunogold labeling and enzyme-linked immuno-sorbent assay. J Invertebr Pathol 1993, 62:99-104.

25. Parkinson J, Guiliano DB, Blaxter M: Making sense of EST sequences by CLOBBing them. BMC Bioinformatics 2002, 3:3I.

26. Suetsugu $Y$, Minami H, Shimomura M, Sasanuma S, Narukawa J. Mita $\mathrm{K}$, Yamamoto K: End-sequencing and characterization of silkworm (Bombyx mori) bacterial artificial chromosome libraries. BMC Genomics 2007, 8:3/4.

27. InterProScan Sequence Search [http://www.ebi.ac.uk/InterPro Scan/]

28. Suh SO, Noda H, Blackwell M: Insect symbiosis: derivation of yeast-like endosymbionts within an entomopathogenic filamentous lineage. Mol Biol Evol 200I, 18:995-1000.

29. Fukuhara T, Koga R, Aoki N, Yuki C, Yamamoto N, Oyama N, Udagawa T, Horiuchi H, Miyazaki S, Higashi Y, et al:: The wide distribution of endornaviruses, large double-stranded RNA replicons with plasmid-like properties. Arch Virology 2006, I5 I:995-1002.

30. Gibbs MJ, Koga R, Moriyama H, Pfeiffer P, Fukuhara T: Phylogenetic analysis of some large double-stranded RNA replicons from plants suggests they evolved from a defective singlestranded RNA virus. J Gen Virol 2000, 8 I:227-233.

31. Miyazaki S, Iwabuchi K, Pak J-Y, Fukuhara T, Nitta T: Selective occurrence of endogenous double-stranded RNAs in insects. Insect Biochem Mol Biol 1996, 26:955-961.

32. Sogawa K: The rice brown planthopper: feeding physiology and host plant interaction. Annu Rev Entomol 1982, 27:49-73.

33. Korayem AM, Fabbri M, Takahashi K, Scherfer C, Lindgren M, Schmidt O, Ueda R, Dushay MS, Theopold U: A Drosophila salivary gland mucin is also expressed in immune tissues: evidence for a function in coagulation and the entrapment of bacteria. Insect Biochem Mol Biol 2004, 34: I297-I 304.

34. Foissac X, Edwards MG, Du JP, Gatehouse AM, Gatehouse JA: Putative protein digestion in a sap-sucking homopteran plant pest (rice brown plant hopper; Nilaparvata lugens: Delphacidae) - identification of trypsin-like and cathepsin B-like proteases. Insect Biochem Mol Biol 2002, 32:967-978.

35. Small G], Hemingway ]: Molecular characterization of the amplified carboxylesterase gene associated with organophosphorus insecticide resistance in the brown planthopper, Nilaparvata lugens. Insect Mol Biol 2000, 9:647-653.

36. Chinzei $Y$, Yano I: Fat body is the site of vitellogenin synthesis in the soft tick, Ornithodoros moubata. J Comp Physiol B 1985 , |55:67|-678.

37. Vontas JG, Small GJ, Hemingway J: Glutathione S-transferases as antioxidant defence agents confer pyrethroid resistance in Nilaparvata lugens. Biochem J 200I, 357:65-72.

38. Liu Z, Williamson MS, Lansdell SJ, Denholm I, Han Z, Millar NS: A nicotinic acetylcholine receptor mutation conferring targetsite resistance to imidacloprid in Nilaparvata lugens (brown planthopper). Proc Natl Acad Sci USA 2005, 1 02:8420-8425.

39. Price DR, Wilkinson HS, Gatehouse JA: Functional expression and characterisation of a gut facilitative glucose transporter, NIHTI, from the phloem-feeding insect Nilaparvata lugens (rice brown planthopper). Insect Biochem Mol Biol 2007, 37: II38-II48.

40. Price DR, Du J, Dinsmore A, Gatehouse JA: Molecular cloning and immunolocalization of a diuretic hormone receptor in rice brown planthopper (Nilaparvata lugens). Insect Mol Biol 2004, I 3:469-480.

4I. Yang Z, Yang $\mathrm{H}, \mathrm{He} \mathrm{G}$ : Cloning and characterization of two cytochrome P450 CYP6AXI and CYP6AYI cDNAs from Nilaparvata lugens Stal (Homoptera: Delphacidae). Arch Insect Biochem Physiol 2007, 64:88-99.

42. Sharma R, Komatsu S, Noda H: Proteomic analysis of brown planthopper: application to the study of carbamate toxicity. Insect Biochem Mol Biol 2004, 34:425-432.

43. Kobayashi T, Noda $\mathrm{H}$ : Identification of $\mathbf{Y}$ chromosomal PCR marker and production of a selected strain for molecular sexing in the brown planthopper, Nilaparvata lugens. Arch Insect Biochem Physiol 2007, 65: I- 10.

44. NCBI BLAST [http://www.ncbi.nlm.nih.gov/blast/download.shtml]
Publish with Bio Med Central and every scientist can read your work free of charge

"BioMed Central will be the most significant development for disseminating the results of biomedical research in our lifetime."

Sir Paul Nurse, Cancer Research UK

Your research papers will be:

- available free of charge to the entire biomedical community

- peer reviewed and published immediately upon acceptance

- cited in PubMed and archived on PubMed Central

- yours - you keep the copyright

Submit your manuscript here:

http://www.biomedcentral.com/info/publishing_adv.asp
BioMedcentral 